\title{
A Comparative Survey of Coding, Multiplexing, and Equalization Techniques Used in Coherent Optical Fiber Communications
}

\author{
John Martin Ladrido ${ }^{\mathrm{a},{ }^{*}, \text { Emmanuel Trinidad }}{ }^{\mathrm{a}, \mathrm{b}}$, James Agustin Molina ${ }^{\mathrm{a}}$, Lawrence Materum ${ }^{\mathrm{a}, \mathrm{c}}$ \\ ${ }^{a}$ Electronics and Communications Engineering Department, De La Salle University, Manila, Philippines \\ ${ }^{b}$ Electronics Engineering Department, Don Honorio Ventura State University, Bacolor, Pampanga, Philippines \\ ${ }^{c}$ International Centre, Tokyo City University, Setagaya, Tokyo, Japan \\ Corresponding author: ${ }^{*}$ john_martin_ladrido@dlsu.edu.ph
}

\begin{abstract}
As the world advances into $5 \mathrm{G}$ networks, significant scientific research accomplishments are being conducted for a communication system that could further enhance the current limit of data transmission capacity. Currently, the communication systems with the highest data rate are optical fiber systems. Due to the recent advancement of coherent optical fiber communications by exploiting time, wavelength, phase, amplitude, polarization, and space, optical engineering can break the petabit barrier data rate. Thus, coherent optical fiber communications is a hot topic due to its very high data rate that could be applied or a requirement in 5G and big data analytics. This paper focuses on a comparative survey of the current applied fundamental techniques in fiber communication channels. These fundamental techniques that could be further studied and exploited to increase the bandwidth performance, decrease the error rate and energy consumption are coding, multiplexing, and equalization. At the end of this paper, a comparative result is discussed to explain the difference among the current techniques in the literature for the optical engineering community to improve collective coding, multiplexing, and equalization in coherent fiber systems.
\end{abstract}

Keywords - Coherent optical communications; coding; multiplexing; equalization.

\section{INTRODUCTION}

As new applications in 5G technology are being substantiated, these new applications need a massive bandwidth requirement for them to work. In the last decade, ground-breaking developments in the data transmission medium with the highest capacity were made, and this transmission medium is fiber optics. As the fiber optics network is expected to be the dominant transmission medium in terms of capacity, it is also expected to be the nextgeneration access network. As fiber optics' capabilities and limits had been stretched, dispersion regarding chromatic and polarization mode is the central issue that needs to be addressed in implementing fiber-optic channels. By addressing dispersion, bandwidth performance is increased, and the bit error rate is reduced. Another major issue that needs to be addressed is the cost-effectiveness of the solution that is being proposed to enhance the current fiber-optic networks. By upgrading the current fiber optic networks and applying cost-cutting, it is crucial to consider that the cheapest way to upgrade these fiber-optic networks is by modifying only the transmitter and receiver ends; without changing or overhauling the optical transmission link [1]-[3].

Due to the advent of digital signal processing and coherent reception over the last decade, a massive data rate of $400 \mathrm{Gbps}$ was possible. Intensive research in coherent optical fiber communications is currently being conducted by researchers, engineers, and scientists to enhance and increase the current capacity transmission in optical fiber networks or go beyond 400 Gbps. Primary researches in advanced error correction, multiplexing, and digital signal processing (DSP) are being conducted beyond the terabits per second (Tbps) data rate and breaking the petabits per second barrier [1]-[3].

The paper addresses the lack of a comprehensive review of coding, multiplexing, and equalization techniques used in coherent fiber communications. This paper mainly focuses on four techniques that could further enhance the capacity of the fiber optics channel. The first technique would be error and line coding. The channel can have more tolerance for higher bit error rates by having a good error coding technique. Simultaneously, repeaters and complicated equalizers to maintain and retrieve the information are not going to be 
necessary. The second technique is multiplexing. Time, wavelength, phase, amplitude, polarization, and space multiplexing techniques are currently being exploited to break the Petabit barrier.

Moreover, the third and last technique would be equalization. Due to the recent discoveries with DSP and combining this with coherent reception, 400 Gbps data rate was possible. Implementing equalization in fiber optics network systems can mitigate both linear and nonlinear effects induced by channel impairments in information or data, being transmitted such as intersymbol interference (ISI) and noise [1], [2].

In Section 2, the latest surveys and studies regarding coherent optical fiber communications are listed and visited. That section also discusses each component that constitutes a coherent optical fiber communications system as well as focuses on the three techniques in detail. Section 3 discusses a summary and realizations about the content of Section 2 . Section 4 contains the conclusion and recommendation regarding this survey paper. The last two sections focus more on finding what is missing in the current surveys and studies and potentially helping future researchers where to start regarding the advancement of current coherent optical fiber communications.

\section{MATERIALS AND METHOD}

\section{A. Existing Surveys, Studies, and Methodology of This Work}

Over the last decade, extensive studies and research were conducted in a coherent optical fiber communication system. Studies and research were conducted in both transmitterreceiver ends and the fiber optical link concerning coding, multiplexing, modulation, equalization techniques, and optical fiber's quantum properties. A list of conducted studies and surveys are as follows:

Morero et al. [4] conducted a study regarding the design tradeoffs and challenges in practical optical transceiver implementations. Their study focused on transceiver implementation that could significantly impact or addressed data rate, spectral efficiency, flexibility, and cost reductions such as digital signal processing, forward error correction, modulation, fundamental limits, complexity, and power consumption.

Fresi et al. [5] have surveyed the advances of optical technologies and techniques specifically for high-capacity communications. The survey was focused on comparing a list of photonic technologies and communication techniques that could increase the capacity of optical networks while at the same time improving cost and power consumption.

Amari et al. [6] conducted a comprehensive survey to combat fiber nonlinearity in 400 Gbps and beyond optical communication systems. Nonlinear impairments were compensated with the use of advanced equalization techniques such as back-propagation and Volterra seriesbased schemes. The survey's primary purpose was to compensate for nonlinear impairments while achieving complexity reduction and performance improvement. Their survey concluded that further studies could be performed in space division multiplexing (SDM) techniques, $\mathrm{C}$ and $\mathrm{L}$ Erbium-Doped fiber amplifier (EDFA), or hybrid EDFA-
Raman amplification to boost data rate capacity.

Tan et al. [7] performed a study in coherent optical sampling to monitor optical signal-to-noise ratio (OSNR) in high-speed optical fiber communications systems. Their proposal is composed of a technology to monitor OSNR in coherent optical communications at the expense of lower complexity and minimal bandwidth requirements, even at a higher symbol rate. They had also added an algorithm that could compensate for the uneven spectrum's influence in the local oscillator to achieve more accuracy.

Tomkos et al. [8] conducted a survey on low-cost and lowpower coherent optical transceivers for $5 \mathrm{G}$ front haul links and datacenter interconnection applications. Their paper surveyed several options to achieve a DSP-chip-less coherent optical fiber communication system for cost-cutting. They had proposed an analog signal processing, consists of alloptical elements for polarization-multiplexed IQ signal coherent detection.

Jing et al. [9] performed a study in optical fiber communications, specifically to the time-domain synchronous orthogonal frequency-division multiplexing (TDS-OFDM) system. Their study comprised of exploiting pseudo-noise (PN) guard intervals to mitigate carrier frequency offset (CFO). Their study resulted in a $10 \%$ higher spectral efficiency than cyclic prefix - orthogonal frequency division multiplexing (CP-OFDM) since there are no training symbols or pilot signals needed in TDS-OFDM.

Zhang et al. [10] and Zhang et al. [11] proposed an equalization technique to mitigate nonlinear channel impairments and improve transmission performance in a nonlinear perspective. Zhang et al. [10] studied the functional-link neural network (FLNN) to combat nonlinear impairments and improve bit error rate (BER) performance in coherent optical fiber communications. At the same time, Zhang et al. [11] studied the multiple layer perceptronartificial neural network (MLP-ANN) for nonlinear equalizer specific in coherent optical OFDM to mitigate nonlinear channel distortions.

Musumeci et al. [12] have done an overview survey in machine learning that could be applied in optical networks to combat nonlinear impairments in the physical layer and apply traffic prediction at the network layer. Their paper gave direction for exploring an innovative optical network by applying machine learning both in DSP optical transceivers and software-defined optical networks (SDON)

The demand for a reliable transmission becomes stringent as operators and vendors aim for high spectral efficiency, dealing with 400 Gbps rate and beyond for a single channel in optical fiber, thus a need for improvements in the techniques to minimize the CAPEX of operators and maximize the capabilities of existing optical infrastructures. One key enabler of a higher transmission rate is the use of forward error correction (FEC). A brief understanding and tutorial on FEC in optical communications are provided by [13]. A survey of FEC codes and their evolution in time from firstgeneration FEC with their strengths used in optical fiber is presented in the work of [14], which also provided state of the art FEC for 100G systems and beyond. A comparison and 
fundamentals of low-density parity-check (LDPC) codes both in a block and convolutional structure are shown with design guidelines for fast convergence by Leven and Schmalen [15]. A combination of coding and modulation are also known as coded modulation with advanced LDPC structure with implementations on Field Programmable Gate Array (FPGA), is discussed by Djordjevic [16]. A more in-depth presentation of fundamentals in [17] on joint FEC and modulation as well as tradeoffs in hardware complexity.

The research of [18] experimented and simulated $160 \mathrm{~Gb} / \mathrm{sx} 80$-channel WDM derived from coherent optical OFDM. The research results show that WDM channels at $12.8 \mathrm{~Tb} / \mathrm{s}$ have a $\mathrm{Q}$ of over $15.0 \mathrm{~dB}$ for $1000 \mathrm{~km}$-long transmission using a standard single fiber. It was found out that WDM derived from coherent optical OFDM was able to maximize spectrum resources and suppressed dispersion and nonlinear effects in the fiber compared to the conventional WDM system.

The research of [19] presented a hybrid multiplexed system which contains four-channel optical time domain multiplexing and two-wavelength division multiplexing. The simulations were performed using $40 \mathrm{Gbps}$ of data rate, and for the linear loss, Erbium-doped fiber amplifiers (EDFA) were used. The systems were able to reach $1,150 \mathrm{~km}$, and a higher spectral efficiency was reached; furthermore, the system cost was reduced. It was also found that it is possible to design an $8 \times 40$ Gbps system using two optical sources.

The research of [20] analyzes the performance of the Optical time-division multiplexing (OTDM) link at 40 Gbps. The research simulates the four-channel OTDM system at a 40 Gbps data rate using RZ and NRZ electrical pulses; thus, dispersion compensating fibers (DCF) were used. The results show that the system could reach $343 \mathrm{~km}$ using single-mode fiber for both electrical pulses. Moreover, it was found out that RZ has a higher Bit error rate and Q-factor compared to NRZ.

The research of [21] proposed a coherent ultra-densewavelength division multiplexing(WDM)-PON for $\lambda$-to-theuser access. The research utilized OOK-NRZ modulation and its architectures. The research could get as low as $-52 \mathrm{dBm}$ at $1 \times 10^{-3} \mathrm{BER}$ with a data rate of $1.25 \mathrm{Gbps}$ while $-49 \mathrm{dBm}$ for directly modulated laser. The research also proves that the optical access system of ultra-dense WDM spacing with a 50$\mathrm{dB}$ loss budget compatible with installed distribution networks is splitter-based.

The research of [22] compares probabilistic shaping (PS) 64-QAM against hybrid 32/64 QAM in a $400 \mathrm{G}$ per channel $50 \mathrm{GHz}$ WDM system. The research reached $990 \mathrm{~km}$ and improved $83 \%$ transmission distance compared with regular64 QAM. PS-64QAM can have a $1.6 \mathrm{~dB}$ OSNR gain compared to the hybrid 32/64 QAM, a 37.5\% improvement at the same entropy.

The different works of literature contain each related topic to be discussed in this paper. The works of literature presented variations of coding techniques, equalization techniques, and multiplexing techniques. The works of literature show some performance, surveys, and evaluations of the said techniques.

The following subsection discusses the block diagram of the coherent optical fiber communication system.

\section{B. Block Diagram of Coherent Optical Fiber Communication System}

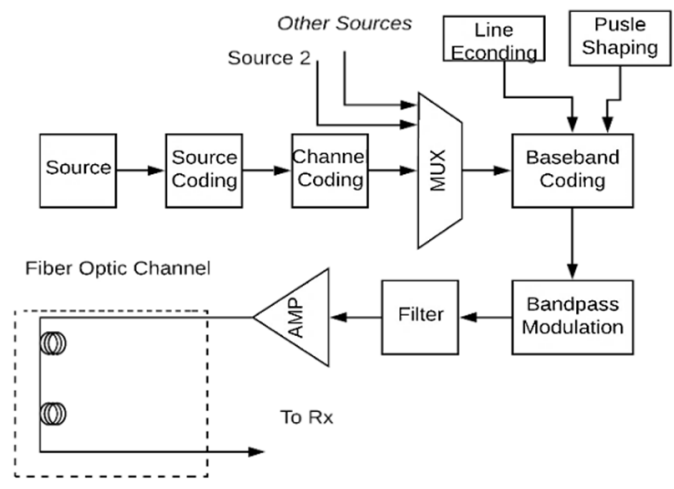

Fig. 1 Coherent Optical Fiber Communication System Transmitter [1]

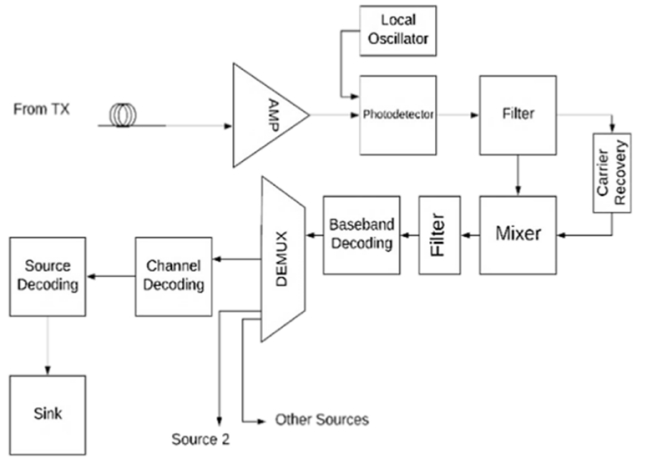

Fig. 2 Coherent Homodyne Receiver [1]

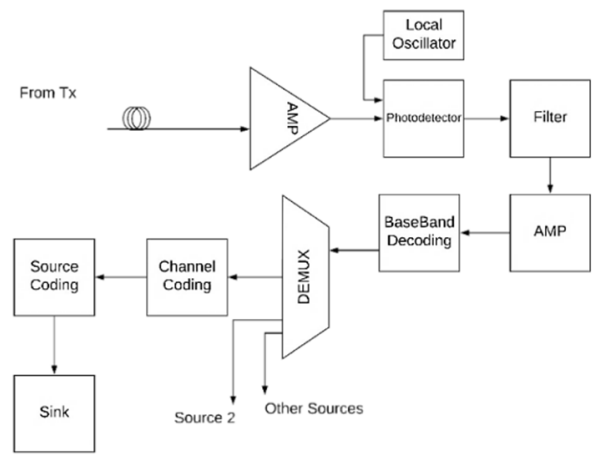

Fig. 3 Coherent Heterodyne Receiver

Fig. 1 to Fig. 2 presents a block diagram of an optical fiber communication (OFC). It can be observed that it may compare closely to that of a wireless system. The reemergence of the research in coherent reception in OFC made the possibility of multilevel formats. In this paper, the authors discuss some fundamentals and surveys of Channel coding, Baseband, and Bandpass Modulation, and DSP. The construction of this paper is subdivided into sections that discuss important enabling technologies for a coherent system. Channel coding involves the precoding of data to induce redundant bits that protect the information from unwanted and unavoidable impairments in the channel, which are also decoded at the receiver if left unaddressed. Multiplexing combines different signals from different sources to input more information through the channel. Modulation in baseband and passband exploits multiple 
dimensions of the carrier signal, particularly the phase in the coherent reception that allows multilevel formatting in encoding information in the signal that dramatically enhances the data rate. The OFC system's receiving end lies in the equalization part. The DSP plays a vital role in equalizing signals to mitigate intersymbol interferences (ISI) due to modulation and pulse shaping interchannel interferences induced by multiplexing. In the receiver part, the blocks presented are reversed in the process of recovering the transmitted information.

The key factor in coherent optical communications is its coherent feature in detection; in general, reception demodulates incoming signals using a local oscillator (LO) [23]. There are two ways for reception techniques, namely the homodyne and the heterodyne. The difference between the two techniques lies in the carrier signals' frequencies and the local oscillator [1].

Homodyne reception or synchronous detection requires an optical phase lock loop (OPLL) to recover the received signals' phase and frequency. The received signal's phase and frequency are locked to the LO, and the signal's absolute phase and frequency are measured relative to that of the LO [1]. Fig. 2 shows the schematic diagram of a homodyne receiver.

Heterodyne reception, or termed as asynchronous detection, does not require OPLL; to add, Heterodyne LO is approximately the same as that of the receiving signals. The received optical signals are mixed with an intermediate frequency (IF) that is about two or three times that of the $3 \mathrm{~dB}$ passband; then, a phase lock loop (PLL) is used in the electrical domain to retrieve the electronic signal at a lower carrier frequency [1]. Fig. 3 shows the schematic diagram of a heterodyne receiver.

Moreover, differential or self-homodyne reception is used when there is no LO used to demodulate the digital optical signals; furthermore, the technique is referred to as the autocorrelation reception process self-heterodyne detection [1].

In comparing the two detection techniques, homodyne detection has a potential 3-dB improvement in SNR and has reduced receiver bandwidth requirement compared to heterodyne detection. The 3-dB improvement in homodyne detection is caused by reducing the receiver bandwidth [23].

In an optical fiber communication system, it is necessary to have a high (Quality factor) Q-factor and less BER. Q-factor provides a suitable measure of the entire communication system. In an optical fiber, the Q factor considers factors that degrade signals such as chromatic dispersion, material dispersion, losses, noise, nonlinearity property, or any polarization; and these factors result in several bit errors in the fiber link. In general, the higher the Q-factor, the lower the occurrence of bit error, which results in a lower probability of BER; besides, higher Q-factors result in greater SNR. To add, Q-factor is a dimensionless parameter [24].

BER is the probability of an error bit to occur in an optical fiber transmission system; in the same way, BER is defined as the ratio of error bits to the total number of bits transmitted. BER is considered in evaluating a transmission system's performance apart from the optical signal-to-noise ratio (OSNR). It is stated in [1] that an optical fiber system of a transmitted bit of $1 \times 10^{-10}$ with a BER of $1 \times 10^{-9}$ is considered as "error-free." BER and Q-factor relationship can be defined as follows [2] [25], where the erfc denotes the complementary error function.

$$
\begin{aligned}
\operatorname{BER} & =\frac{1}{2} \operatorname{efrc}\left(\frac{\mathrm{Q}}{\sqrt{2}}\right) \\
& \cong \frac{\mathrm{e}^{\left(-\frac{\mathrm{Q}^{2}}{2}\right)}}{\mathrm{Q} \sqrt{2 \pi}}
\end{aligned}
$$

\section{Techniques Used in Coherent Optical Fiber Communication System \\ 1) Coding Techniques:}

a) Mechanism of Coding

In Figure 1, the block diagram of optical fiber communication (OFC) is presented. This section provides the primary mechanism of channel coding. Presented first in the diagram is the source coding, which deals with the compression of data transmitted; on the other hand, channel coding adds redundancy bits for error control against timevarying nonlinear properties of the channel. Error control can be done by Automatic Repeat Request (ARQ) for systems that have bidirectional or full-duplex transmission, which only allows error detection. Forward Error Correction (FEC) schemes can correct specific errors during transmission without resending the data, hence enhancing the reliability and accuracy of a communication system with low latency compared to ARQ. Since fiber optics are designed for longhaul operations, FECs are highly preferred over ARQ.

Implementation of FEC can be applied in three methods, block, convolutional, or combination of both are known as concatenated schemes. Block codes have a finite and constant length of codewords, which are defined as $n$ as the number of information bits and $k$ as the total length of the block, where $n-k$ yields the total number of parity bits added to the block, and the ratio $\frac{k}{n}$ gives the code rate $R$. In optical systems, the parameter of comparison is in terms of overhead is given by $O H=100\left(\frac{n}{k}-1\right) \%$. Overhead of above $20 \%$ is now being recommended by the Optical Internetworking Forum (OIF) to standard for Soft Decision (SD) FEC schemes. While block coding introduces, check bits to a block of bits to introduce the codeword. The convolutional scheme is continuous, which introduces check bits after every bit in the memory that uses a shift register for memory.

Due to different fiber optic channel abnormalities such as dispersion, noise, attenuation, and nonlinear effects, errors in the signal are inevitable and results in the misrepresentation or loss of information received. Shannon's channel capacity theory gave reliable transmission ideas in a noisy channel known as the Shannon limit [26]. This limit has been approached in the last decades using modern, sophisticated codes parallel with computing resources development. FEC's basic optical systems' basic parameters are as follows, coding overhead rate, net coding gain, and post-FEC BER threshold. Coding gain is a measure of attainable energy per information bit to the noise spectral density ratio denoted by $\frac{E_{b}}{N_{o}}$. The parameters are hereby summarized in Table 1 for comparisons of tradeoffs. 
The decision point and decoding method are also considered. It may be based on certain thresholds where $1 \mathrm{~s}$ or 0 s occur or the probability if 1 or 0 occurs with the Loglikelihood Ratio (LLR) and with multiple quantization levels of $2^{m}$. These are namely Hard Decision FEC (HD-FEC) and Soft Decision FEC (SD-FEC), respectively. SD-FEC has gain popularity in parallel with the development of coherent optical technology. These SD-FEC gains favor by using statistical methods that provide a more confident decoding process using confidence bits at the expense of latency. FEC's two types of decision processes can also be used with the desired tradeoff between complexity bandwidth, power consumption, coding gain, and achievable distance. As reported by [14], a 1- to 2-dB coding gain can yield an additional $20-40 \%$ in the total achievable distance. With these said improvements of SD-FECs, HD FEC can also be used solely or concatenated to clean up residual errors brought by SD decoding.

TABLE I

KEY PARAMETERS OF FECS

\begin{tabular}{|c|c|c|c|}
\hline Parameters & Description & Benefits & Tradeoff \\
\hline $\begin{array}{l}\text { Net Coding } \\
\text { Gain } \\
\text { (NCG) }\end{array}$ & $\begin{array}{l}\text { the efficiency of } \\
\text { the coding } \\
\text { technique }\end{array}$ & $\begin{array}{l}\text { more } \\
\text { extended } \\
\text { maximum } \\
\text { range and } \\
\text { capacity }\end{array}$ & complexity \\
\hline $\begin{array}{l}\text { Overhead } \\
\text { Rate (OH) }\end{array}$ & $\begin{array}{l}\text { the ratio of } \\
\text { redundant bits to } \\
\text { the number of } \\
\text { information bits } \\
\text { computed }\end{array}$ & $\begin{array}{l}\text { OSNR } \\
\text { compensatio } \\
\mathrm{n} \text { and } \\
\text { transmission } \\
\text { reach }\end{array}$ & $\begin{array}{l}\text { spectra/ data } \\
\text { rate }\end{array}$ \\
\hline $\begin{array}{l}\text { Soft } \\
\text { Decoding } \\
\text { (SD) }\end{array}$ & $\begin{array}{l}\text { uses a higher } \\
\text { quantization level } \\
\text { for the decision } \\
\text { process of } \\
\text { decoding }\end{array}$ & $\begin{array}{l}\text { coding gain } \\
\text { and reach }\end{array}$ & $\begin{array}{l}\text { complexity, } \\
\text { power } \\
\text { consumptio } \\
\text { n, and cost }\end{array}$ \\
\hline $\begin{array}{l}\text { Hard } \\
\text { Decoding } \\
\text { (HD) }\end{array}$ & $\begin{array}{l}\text { uses bits " } 1 \text { " or } \\
\text { " } 0 \text { " with a certain } \\
\text { threshold for } \\
\text { decoding the } \\
\text { transmitted } \\
\text { symbol }\end{array}$ & $\begin{array}{l}\text { moderate } \\
\text { gain and } \\
\text { low cost }\end{array}$ & latency \\
\hline
\end{tabular}

\section{b) Coding in Coherent Optical Fiber Communications}

The coherent technology in OFC paved the way for the use of high-level or multilevel modulation formats that are used in wireless communications. However, the multilevel modulation format is more susceptible to noise due to the small distances in the decision region concerning the constellation points; thus, the need for robust FEC. In the rise of coherent detection, SD-FEC gained popularity due to its multilevel quantization property, enhancing coding gains. These SD-FEC are categorized as the $3^{\text {rd }}$ Generation FEC. Implementation of SD FEC requires a higher overhead, yielding high coding gain and better performance with the expense of a more complex decoding process and power consumption.

Specific parameters have also emerged due to probabilistic nature like mutual information and generalized mutual information. Probabilistic amplitude shaping introduces a concatenation of an outer code, a distribution matcher, and an inner FEC code experiment [27]. Various techniques have been developed in the past decade regarding FEC and are focused on the popular codes, the LDPC codes by Gallager [28]. LDPC codes can be termed as universal codes due to their flexibility regardless of channel type [29]. LDPC codes can also be modified by their code rates when dealing with essential parameters such as power dissipation and other factors [16] pointed out the attractive, adequately designed LDPC codes. Fig. 4 shows a parity check matrix of an LDPC decoder with a tanner graph representation where most LDPC are analyzed using this graph.

Adaptive FEC selection or rate adaptable codes proposed an algorithm for elastic optical networks. It can minimize overhead rate based on the calculated OSNR of any light path, saving the spectra and computational power used for the overhead of robust FEC schemes for different channel conditions. Rate adaptive FECs are also flexible based on the distance of transmissions, the high overhead for the long haul, and the low overhead otherwise. These FEC schemes are combined with modulation schemes, which are popularly known as Coded Modulation (CM) schemes, to optimize processes needed for optical communication. Recent advances such as Super Coherent Technologies are on the hotspot with the introduction of Probabilistic Constellation Shaping (PCS) and FEC [30], [31]. The said technologies require an adaptive scheme of FEC known as multi-rate FEC. Probabilistic shaping maps the constellation property of modulation that changes symbol distribution modeled to a Gaussian distribution, in which low amplitudes are sent more often than that of far from the constellation.

TABLE II

FEC SCHEMES FOR COHERENT OFC

\begin{tabular}{lllll}
\hline FEC Scheme & Brief Description/ Key Features & $\begin{array}{l}\text { Decision } \\
\text { Point }\end{array}$ & Overhead & Main Advantages \\
\hline $\begin{array}{l}\text { Two Iteration } \\
\begin{array}{l}\text { Concatenated BCH } \\
\text { code [32] }\end{array}\end{array}$ & $\begin{array}{l}\text { outer BCH [3904,3820] with inner } \\
\text { BCH [2040,1952] with block } \\
\text { Turbo Product Code }\end{array}$ & HD & $6.81 \%$ & low complexity decoder \\
$\begin{array}{l}\text { (TPC)/Block Turbo } \\
\text { concatenated product codes with }\end{array}$ & HD & $20 \%$ & fast convergence with a small \\
$\begin{array}{l}\text { Code (BTC) [33] } \\
\begin{array}{l}\text { LDPC CC } \\
\text { (convolutional }\end{array}\end{array}$ & $\begin{array}{l}\text { spatially coupled codes LDPC } \\
\text { (10032,4,24), decoder latency is } \\
\text { reduced by half using message passing } \\
\text { algorithm (MPA) }\end{array}$ & SD - 4 bits & $20 \%$ & shorter codeword length \\
\hline
\end{tabular}




\begin{tabular}{|c|c|c|c|c|}
\hline $\begin{array}{l}\text { Concatenated } \\
\text { LDPC and Reed } \\
\text { Solomon (RS) } \\
\text { codes }[35]\end{array}$ & $\begin{array}{l}\text { concatenation of LDPC }(9216,7936) \\
\text { inner code with girth } 6 \text { and RS } \\
(992,956) \text { as outer code }\end{array}$ & SD - 2 bits & $20.5 \%$ & $\begin{array}{l}\text { low complexity with high error- } \\
\text { correcting performance }\end{array}$ \\
\hline $\begin{array}{l}\text { Concatenated QC- } \\
\text { LDPC and SPC } \\
\text { codes[36] }\end{array}$ & concatenated QC-LDPC and SPC codes & SD- 4 bits & $20.50 \%$ & enables high-speed implementation \\
\hline $\begin{array}{l}\text { Single Quasi-Cyclic } \\
\text { (QC) LDPC [37] }\end{array}$ & $\begin{array}{l}\text { single non concatenated QC- LDPC } \\
(18360,15300) \text { with girth } 8\end{array}$ & SD & $20 \%$ & no error floor and low complexity \\
\hline $\begin{array}{l}\text { QC-LDPC codes } \\
\text { with Regular } \\
\text { Column Partition } \\
\text { (RCP) [38] }\end{array}$ & $\begin{array}{l}\text { LDPC long codewords with RCP } \\
\text { allowing an efficient parallel } \\
\text { implementation }\end{array}$ & SD - 5 bits & $20 \%$ & low error floor and tolerable latency \\
\hline $\begin{array}{l}\text { Spatially Coupled } \\
\text { LDPC [39] }\end{array}$ & $\begin{array}{l}\text { concatenated spatially coupled LDPC } \\
(38400,30832) \text { with a BCH code } \\
(30832,30592)\end{array}$ & SD - 4 bits & $25.50 \%$ & $\begin{array}{l}\text { high performance on error floor and } \\
\text { waterfall region }\end{array}$ \\
\hline $\begin{array}{l}\text { Concatenated non } \\
\text { binary LDPC and } \\
\text { HD-FEC [40] }\end{array}$ & $\begin{array}{l}\text { non binary LDPC }(2304,20480) \text { and } \\
\operatorname{RS}(255,239)\end{array}$ & $\begin{array}{l}\mathrm{SD}-5 \\
\text { bits/HD }\end{array}$ & $20.50 \%$ & $\begin{array}{l}\text { good performance against burst } \\
\text { errors }\end{array}$ \\
\hline $\begin{array}{l}\text { Triple Concatenated } \\
\text { FEC [41], [42] }\end{array}$ & $\begin{array}{l}\text { LDPC inner codes with a pair of } \\
\text { concatenated HD block codes }\end{array}$ & SD - 3bits & $20.50 \%$ & high net coding gain \\
\hline Staircase codes [43] & $\begin{array}{l}\text { binary generalized LDPC a } \\
\text { combination of recursive convolutional } \\
\text { and block coding }\end{array}$ & HD & $6.70 \%$ & $\begin{array}{l}\text { low latency encoding with variable } \\
\text { latency in decoding }\end{array}$ \\
\hline $\begin{array}{l}\text { Multidimensional } \\
\text { Turbo Product } \\
\text { codes (MTPC) [44] }\end{array}$ & generalization of Turbo Product codes & HD & $20 \%$ & low complexity \\
\hline $\begin{array}{l}\text { Generalized LDPC } \\
\text { (GLDPC) }[44]\end{array}$ & $\begin{array}{l}\text { with serial concatenation component } \\
\text { code of RS and MTPC }\end{array}$ & HD & $20 \%$ & low complexity \\
\hline $\begin{array}{l}\text { Super Product BCH } \\
\text { [45] }\end{array}$ & $\begin{array}{l}\mathrm{BCH}(3908,3824) \text { as row code and } \\
\mathrm{BCH}(2031,1954) \text { as column codes }\end{array}$ & HD & $7 \%$ & $\begin{array}{l}\text { low complexity, better burst error } \\
\text { correction }\end{array}$ \\
\hline $\begin{array}{l}\text { Continuously } \\
\text { Interleaved BCH } \\
\text { (CI-BCH) [46] }\end{array}$ & Based on interleaved BCH $(1020,988)$ & HD & $7 \% / 12 \% / 20 \%$ & low complexity/ for burst error \\
\hline $\begin{array}{l}\text { Unequal Error } \\
\text { Protection (UEP- } \\
\mathrm{BCH})[47]\end{array}$ & $\begin{array}{l}\text { a modified product codes that checks on } \\
\text { the normal and check bits using } \\
\mathrm{BCH}(1632,1588) \times\{\mathrm{BCH}(1280,1236) \\
+\mathrm{BCH}(1280,1225)\}\end{array}$ & HD & $7 \%$ & no error floors and high NCG \\
\hline $\begin{array}{l}\text { Swizzle (Spiral } \\
\text { Interleaved Turbo } \\
\text { FEC) }[48]\end{array}$ & $\begin{array}{l}\text { inspired by an LDPC structure in a } \\
\text { spiral pattern }\end{array}$ & HD & $6.70 \%$ & $\begin{array}{l}\text { eliminates error floor and low } \\
\text { latency }\end{array}$ \\
\hline $\begin{array}{l}\text { Braided BCH codes } \\
\text { [49] }\end{array}$ & spatially coupled codes LDPC & HD & $7 \%$ & low complexity \\
\hline $\begin{array}{l}\text { Concatenated } \\
\text { LDPC-Staircase } \\
\text { Codes [50] }\end{array}$ & $\begin{array}{l}\text { leaves some inner codeword uncoded, } \\
\text { thus reducing complexity }\end{array}$ & SD & $20 \%$ & low complexity \\
\hline $\begin{array}{l}\text { Concatenated } \\
\text { LDGM-staircase } \\
\text { FEC [51] }\end{array}$ & $\begin{array}{l}\text { Pareto optimized Low-Density } \\
\text { Generator Matrix (LDGM) } \\
\text { concatenated with Staircase Codes }\end{array}$ & SD & $20 \%$ & low complexity \\
\hline $\begin{array}{l}\text { Improved Low } \\
\text { power LDPC [52] }\end{array}$ & $\begin{array}{l}\text { Priori Assisted Adaptive Degeneration } \\
\text { (PAD) algorithm for decoding }\end{array}$ & SD- 5 bits & $20 \%$ & low power \\
\hline $\begin{array}{l}\text { Regular Column } \\
\text { Partition(RCP) } \\
\text { Quasi-Cyclic Non- } \\
\text { Concatenated } \\
\text { LDPC code [53] }\end{array}$ & $\begin{array}{l}\text { variable-rate code with adaptive } \\
\text { algorithm and good performance in } \\
\text { various channel condition }\end{array}$ & - & $20,18.18,16.66 \%$ & $\begin{array}{l}\text { adaptive power consumption and } \\
\text { programmability of } \mathrm{OH}\end{array}$ \\
\hline $\begin{array}{l}\text { Iteration aware } \\
\text { LDPC codes [54] }\end{array}$ & $\begin{array}{l}\text { LDPC codes with limited iterations in } \\
\text { decoding }\end{array}$ & SD & $25 \%$ & reduced complexity \\
\hline $\begin{array}{l}\text { Multiple Structured } \\
\text { Spatially Coupled } \\
\text { LDPC with BCH } \\
\text { codes [55] }\end{array}$ & $\begin{array}{l}\text { concatenated MSSC-LDPC } \\
(38400,30832) \text { and BCH }(30832 \text {, } \\
30592)\end{array}$ & SD & $20.5 \%$ and 25.55 & $\begin{array}{l}\text { low error floor and suppressed } \\
\text { residual error }\end{array}$ \\
\hline
\end{tabular}




\begin{tabular}{|c|c|c|c|c|}
\hline $\begin{array}{l}\text { Rate Adaptive FEC } \\
{[56]}\end{array}$ & $\begin{array}{l}\text { concatenated row split LDPC and } \\
\text { shortened } \mathrm{BCH}\end{array}$ & SD - 4 bits & $25.5 \%$ to $149.5 \%$ & $\begin{array}{l}\text { no degradation as baud rates } \\
\text { increases }\end{array}$ \\
\hline $\begin{array}{l}\text { Hybrid Polar LDPC } \\
\text { CM [57] }\end{array}$ & $\begin{array}{l}\text { four-dimensional CM scheme Hybrid } \\
\text { Polar combined with Non-Binary } \\
\text { LDPC and Probabilistic Shaping }\end{array}$ & SD & $7 \%$ & $\begin{array}{l}\text { low complexity and reduced } \\
\text { transmit power }\end{array}$ \\
\hline $\begin{array}{l}\text { Rate Adaptive } \\
\text { LDPC [58] }\end{array}$ & $\begin{array}{l}\text { Staircase structure with LDPC as } \\
\text { component code }\end{array}$ & $\mathrm{SD} / \mathrm{HD}$ & Adaptive & $\begin{array}{l}\text { low energy and can mitigate error } \\
\text { floor }\end{array}$ \\
\hline $\begin{array}{l}\text { LDPC with } \\
\text { Probabilistic } \\
\text { Shaping [59] }\end{array}$ & $\begin{array}{l}\text { LDPC inner code with a Staircase outer } \\
\text { code }\end{array}$ & - & - & increase in transmission distance \\
\hline $\begin{array}{l}\text { Non-Binary LDPC } \\
\text { Coded Modulation } \\
\text { (NB-LDPC-CM) } \\
{[60]}\end{array}$ & $\begin{array}{l}\text { rate-adaptive by varying submatrices } \\
\text { row weights and adaptive to varying } \\
\text { channel condition }\end{array}$ & SD & Adaptive & low complexity and latency \\
\hline $\begin{array}{l}\text { All-optical FEC } \\
{[61],[62]}\end{array}$ & $\begin{array}{l}\text { convolutional FEC }(7,5) 8 \text { coding } \\
\text { scheme in the optical domain using } \\
\text { optical XOR gates }\end{array}$ & - & - & $\begin{array}{l}\text { no conversion needed with high } \\
\text { coding gain }\end{array}$ \\
\hline
\end{tabular}

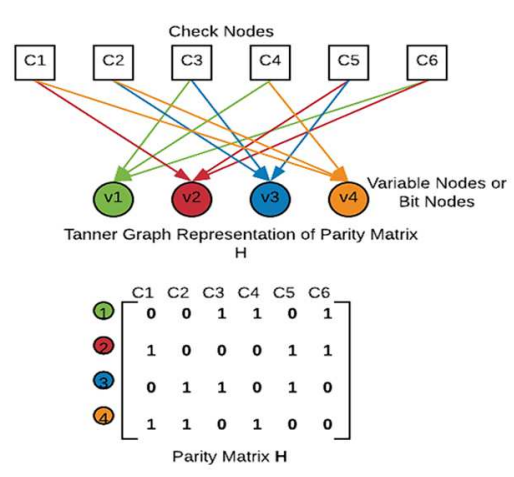

Fig. 4 Parity Check Matrix and Corresponding Tanner Graph

\section{c) Comparison of different Coding Techniques for Coherent Optical Fiber Communication}

Table 2 presents vast literature, proposals, and field simulations of FEC schemes in OFC. It can be observed that most of the schemes are based on the LDPC structure, as these codes are flexible and non-proprietary. The overhead or the redundancy ratio for SD is seen to be $20 \%$, which implies robustness against noise and can be used for long-haul transmission at the expense of complexity. Today, emerging research topics are the joint optimization of FEC technique and modulation and applying probabilistic shaping included in the final part of the table for reference. Choosing the best FEC depends on the application, in the metro, data center interconnect, or access networks and the table presents state of the art and advanced coding schemes to be a starting point.

\section{2) Multiplexing Techniques:}

\section{a) Mechanism of Multiplexing}

Multiplexing is a technique that combines various signals onto a single channel (fiber) to maximize the transfer of information over optical fiber communication. Multiplexing technologies include wavelength division multiplexing (WDM), optical time-division multiplexing (OTDM), hybrid multiplexing, and optical orthogonal frequency division multiplexing (OFDM). Wavelength Division Multiplexing (WDM). To increase network capacity, WDM maximizes the entire bandwidth in optical fiber. The technique combined several signals $(\lambda 1, \lambda 2, \lambda 3, \ldots, \lambda N)$ from a different transmitter in a multiplexer, and the combined signal is transmitted on the same fiber; in this case, each channel has its dedicated bandwidth, and all signals have the same time of arrival [63]. Fig. 5 shows an overview of a WDM system.

A type of WDM was developed for single-mode fiber named Dense WDM (DWDM). DWDM is primarily used with optical signals multiplexed in the $1.55 \mu \mathrm{m}$ wavelength region with erbium-doped fiber amplifiers (EDFAs) to increase the system's capacity. For the long-haul DWDM system, EDFA's and dispersion compensation are needed to offset optical signal power losses caused by passive devices and optical wavelength demultiplexers [senior]. An example of generic long-haul DWDM that uses EDFA and chromatic dispersion compensator is shown in Fig. 6 below. DWDM primarily utilizes narrow channel spacing such as $1.6 \mathrm{~nm}(200$ $\mathrm{GHz}), 0.8 \mathrm{~nm}(100 \mathrm{GHz})$, and $0.4 \mathrm{~nm}(50 \mathrm{GHz})$. Hence, the single optical fiber can accommodate many wavelength channels using DWDM [23].

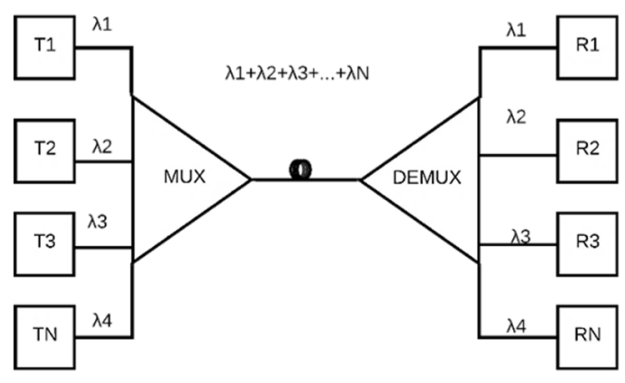

Fig. 5 WDM System [63]

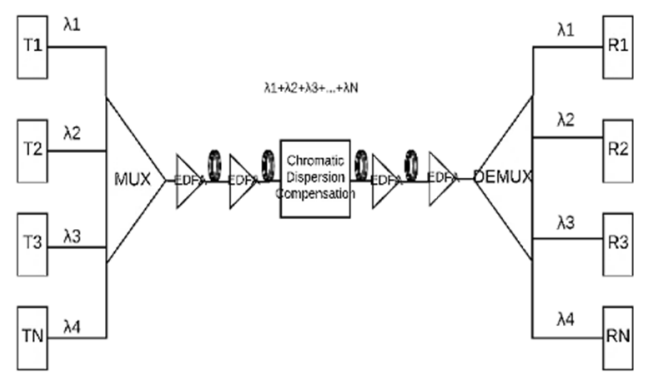

Fig. 6 DWDM System [23] 


\section{b) Optical Time Division Multiplexing}

Time Division Multiplexing (TDM) is a technique commonly used in digital multiplexing. TDM allows one or more transmitters to transmit low or medium bit rates on the same high-speed channel [63]. The narrow pulses from different channels are interleaved and transmitted sequentially; thus, the single-fiber link bandwidth utilization increases [23]. However, TDM imposes limitations on the bandwidth utilization of a single-mode fiber link [23]. Optical Time Division Multiplexing (OTDM) is an alternative technology developed to increase the digital optical fiber system bit rate to exceed the limits. OTDM system combines optical data at basic bit rate $B$ and the number of channels $N$ in the time domain to obtain a higher associated bit rate $(N \mathrm{x}$ $B$ ) [63]. Despite using different optical sources, the signals are emitted at the same optical wavelength [23]. Fig. 7 below shows the ODTM of the N-channel Fiber system. Fig. 7 shows that a single clock drove the transmitters. The pulses from each transmitter are synchronized and delayed by a fraction of clock period $\Delta \mathrm{t}$. Crosstalk can be avoided if the source is able to generate optical pulses with a duration of $<1 / \mathrm{N}$ of the clock period [63].

\section{c) Optical Frequency Division Multiplexing}

Frequency Division Multiplexing or FDM uses multiple subcarriers instead of a single carrier to increase channel efficiency. The subcarriers are centered by data signal when modulated, and the modulated subcarriers or subcarrier multiplexed signals parallel to each other are then transmitted simultaneously. Guard bands separate subcarriers to avoid overlapping. At the receiver side, the subcarriers are demodulated with filters to separate the frequency bands [23]. Fig. 8 below shows FDM with six subcarriers separated by the guard bands.

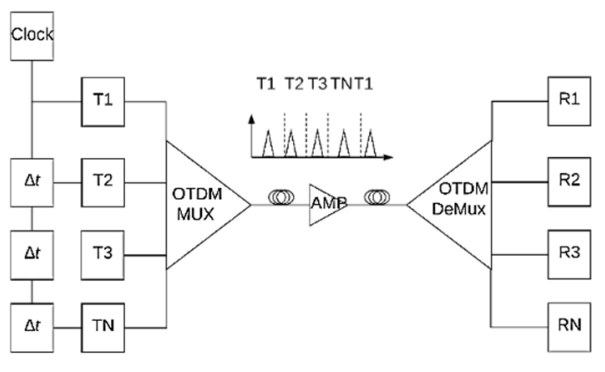

Fig. 7 OTDM System [63]

\section{d) Orthogonal Frequency Division Multiplexing (OFDM)}

OFDM, a multicarrier transmission technique, is a particular case of FDM. OFDM subcarriers frequencies are orthogonal (i.e., perpendicular) to each; thus, the subcarriers do not interfere with each other. In this case, OFDM can compress multiple modulated carriers hence removing the guardband requirements and reducing bandwidth [23]. Fig. 9 below shows the spectrum of OFDM.

In comparison with Fig. 8, both figures have the same span of the spectrum. However, OFDM has better bandwidth saving compared to FDM. OFDM utilizes the inverse fast Fourier transform (IFFT) for its modulation and fast Fourier transform (FFT) for demodulation. Moreover, the perpendicularly positioning of the subcarriers results from FFT operation, hence the name orthogonal FDM [23].

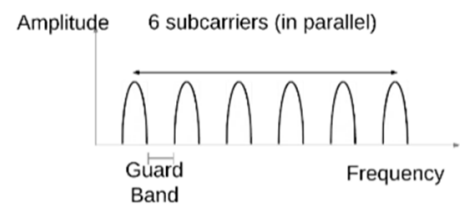

Fig. 8 Optical Frequency Division Multiplexing [23]

\section{e) Space-division Multiplexing}

Another technique in multiplexing is space-division multiplexing (SDM). The technique utilizes multi-core fibers (MCFs) to increase the optical transmission capacity; generally speaking, the capacity can be increased by increasing the number of cores [64].

Hybrid Multiplexing. Hybrid multiplexing is a technique that combines different optical signal multiplexing techniques. This technique is used to combine each technique's advantages; in the same way overcomes drawbacks by combining a specific technique to another [23],[63].

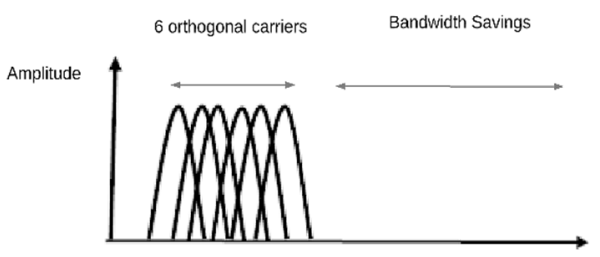

Fig. 9 OFDM Spectrum [23]

\section{f) Multiplexing in Coherent Optical Fiber Communications}

The multicarrier coherent optical system can be assumed as frequency division multiplexed if each different channel is to be separated by tuning the local oscillator of the receiver; moreover, the coherent system, in which its receiver used optical front-end modules such as Fabry-Pérot interferometer or another optical filter in selecting different optical channels, is considered wave division multiplexed. According to [23], coherent optical transmission's primary advantage is its selectivity of wavelength/frequency in narrow channel spacings; to add, more optical carriers could be employed when using coherent optical receivers capable of being tuned in a specific incoming carrier signal. The coherent optical system has the advantage of utilizing sizeable optical bandwidth while avoiding possible bottlenecks made by the speed of electronics within a single-carrier system [23].

Coherent Optical OFDM (CO-OFDM) was developed to prevent both fiber chromatic dispersion and polarization mode dispersion. Fig. 10 below shows a generic CO-OFDM system. The transmitter block has an RF-OFDM transmitter, which generates a baseband OFDM signal; following this, the OFDM signal is then upconverted to the optical domain with the help of an in-phase and quadrature modulator based on Mach-Zehnder modulators (MZM). The signal is sent to an optical-to-RF downconverter that uses a $90^{\circ}$ optical hybrid and two balanced receivers, and the signal is down-converted from optical OFDM signal back to baseband; after this, RF OFDM receiver process and demodulates the OFDM signal to recover the data [18],[23]. Fig. 10 shows a generic COOFDM system (S/P stands for series-to-parallel, GI for guard interval, and AWG for an array of waveguides). 
TABLE III

PARAMETERS OF MULTIPLEXING TECHNIQUES

\begin{tabular}{|c|c|c|c|c|c|c|c|c|c|}
\hline $\begin{array}{l}\text { Multiplexing } \\
\text { Technique }\end{array}$ & $\begin{array}{c}\text { Number of } \\
\text { Channels/ User }\end{array}$ & $\begin{array}{l}\text { Bit Rate } \\
\text { (Gbps) }\end{array}$ & Modulation & $\begin{array}{l}\text { Length } \\
(\mathrm{km})\end{array}$ & $\begin{array}{c}\text { Pulse } \\
\text { Format }\end{array}$ & $\begin{array}{l}\text { Source } \\
\text { Power }\end{array}$ & $\begin{array}{c}\text { Transmission } \\
\text { Wavelength } \\
\text { (nm) }\end{array}$ & $\begin{array}{c}\text { Minimum } \\
\text { Bit Error } \\
\text { Rate } \\
\text { (BER) }\end{array}$ & $\mathbf{Q}$ \\
\hline OTDM[63] & 4 channels & 40 & Amplitude & 180 & $\mathrm{RZ}$ & $\begin{array}{l}2 \mathrm{dBm} \\
(1.5 \mathrm{~mW})\end{array}$ & 1562 & $7.98 \times 10^{-7}$ & 3.53 \\
\hline DWDM[65] & $\begin{array}{l}32 \text { wavelength } \\
\text { channels }\end{array}$ & 320 & --- & 40 & $\begin{array}{l}\text { RZ-EM } \\
\text { (ext. mod.) }\end{array}$ & $\begin{array}{l}-10 \mathrm{dBm} \\
(1 \mathrm{~mW})\end{array}$ & 1550 & $3.74 \times 10^{-49}$ & 14.6 \\
\hline DWDM[66] & $\begin{array}{l}8 \text { DWDM } \\
\text { channels }\end{array}$ & 80 & --- & 84 & $\mathrm{RZ}$ & $\begin{array}{l}3 \mathrm{dBm} \\
(2 \mathrm{~mW})\end{array}$ & 1550 & $1.87 \times 10^{-49}$ & 14.73 \\
\hline DWDM[66] & $\begin{array}{l}8 \text { DWDM } \\
\text { channels }\end{array}$ & 80 & --- & 84 & NRZ & $\begin{array}{l}7 \mathrm{dBm} \\
(5 \mathrm{~mW})\end{array}$ & 1550 & $8.89 \times 10^{-10}$ & 6 \\
\hline $\begin{array}{l}\text { OTDM-WDM } \\
{[67]} \\
\text { (Hybrid Multiplexing) }\end{array}$ & 384 channels & 240 & Amplitude & 780 & $\mathrm{RZ}$ & $\begin{array}{l}5 \mathrm{dBm} \\
(3.2 \mathrm{~mW})\end{array}$ & 1550 & $2.78 \times 10^{-18}$ & 8.53 \\
\hline $\begin{array}{l}\text { CO-OFDM-WDM [68] } \\
\text { (Hybrid Multiplexing) }\end{array}$ & $\begin{array}{l}512 \text { subcarriers } \\
4 \text { WDM } \\
\text { channels }\end{array}$ & 48 & 4 QAM & 200 & NRZ & $\begin{array}{l}-15 \mathrm{dBm} \\
\text { to } 15 \\
\mathrm{dBm} \\
\text { (varied) }\end{array}$ & 1550 & $1.1 \times 10^{-10}$ & 6.30 \\
\hline
\end{tabular}

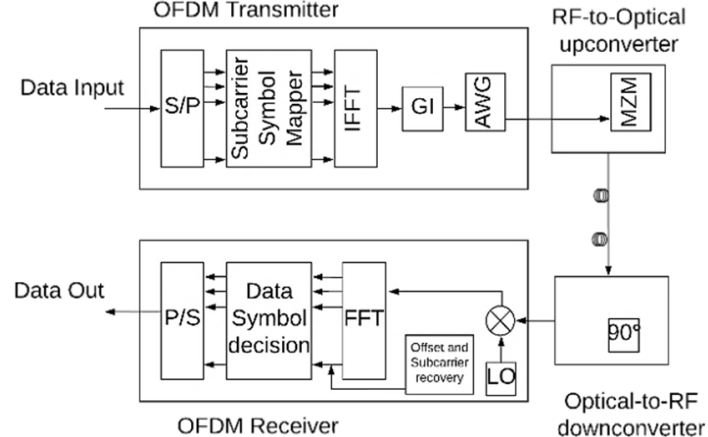

Fig. 10 CO-OFDM system [18],[23]

g) Comparison of Different Multiplexing Techniques for Coherent Optical Fiber Communications

Table 3 shows the different techniques of multiplexing and its parameters from [63] [65]-[68]. These parameters were observed to be common from the literature of various methodologies. For instance, each paper has different considerations and circumstances affecting its systems. These include integration or combination of different techniques such as modulation techniques, the different gain of amplifiers, or different compensation techniques for chromatic dispersion, nonlinear effects, and the like. To add, the considerations mentioned include length. It can be seen in Table 3 that each optical fiber system has a different length.

Thus, the attenuation, which has the units $(\mathrm{dB} / \mathrm{km})$, came into play. Indeed, the longer the length, the higher the attenuation and other parameters such as chromatic dispersion that degrade the fiber optical system's performance. It is not easy to compare the multiplexing techniques due to the differences in the sources' approach. Thus, the bit error rate (BER) and Q-factor are needed to be considered. BER and Qfactor are conventional methods to assess the whole transmission system's performance regardless of differences or methods used in the system.

The parameter that usually first to examine is the bit rate, which tells how many bits are transmitted in a second. However, concluding which multiplexing technique has the highest bit rate is not apparent due to the different number of channels. Dividing the number of channels to the system's total bit rate can show which designed multiplex channel has the highest bit rate.

As can be seen in Table 3, CO-OFDM-WDM and the third DWDM are multiplexing techniques that are in NRZ format; to add, among the three DWDM, the third DWDM or DWDM on NRZ format has the highest power, which is in $7 \mathrm{dBm}$, and it has the lowest BER and Q-factor. Furthermore, it can be seen in Table 3 that CO-OFDM-WDM in NRZ format has a high-power source.

From Table 3, It is ambiguous to conclude which technique has a better Q-factor due to the differences in length. To have a comparison, the authors should establish ground in comparison. The first step is multiplying the Q-factor and the length of the fiber ( $\mathrm{Q} x$ Length). The product is then divided into any arbitrary values of length, obtaining a Q-factor for multiplexing techniques in uniform length. In this case, the difference in fiber length is omitted, and all $\mathrm{Q}$ values are relative to a specific length.

It can be observed in Table 4 that the designed CO-OFDMWDM has the highest bit rate per channel, followed by OTDM and DWDM at $10 \mathrm{Gbps}$, while OTDM-WDM has the lowest value.

TABLE IV

Q-FACTORS OF MULTIPLEXING TECHNIQUES

\begin{tabular}{ccc}
\hline Multiplexing & Length (km) & Bit rate \\
\hline OTDM & 180 & $10 \mathrm{Gbps} /$ channel \\
DWDM & 40 & $10 \mathrm{Gbps} /$ channel \\
DWDM & 84 & $10 \mathrm{Gbps} /$ channel \\
DWDM & 84 & $10 \mathrm{Gbps} /$ channel \\
OTDM-WDM & 780 & $625 \mathrm{Mbps} /$ channel \\
CO-OFDM-WDM & 200 & $12 \mathrm{Gbps} /$ channel \\
\hline
\end{tabular}

Moreover, the arbitrary value of length to be chosen must be relative to each length present from the above tables. The last column of Table 5 shows the Q divided by $228 \mathrm{~km}$. It can be observed that the OTDM-WDM system still the highest value of $\mathrm{Q}$, but it has the lowest bit rate per channel among the multiplexing techniques. Even though CO-OFDM-WDM 
shows a lower Q-factor than OTDM-WDM, CO-OFDMWDM shows a higher bit rate among all the techniques. OTDM and the other two DWMD [65] and [66] have Qfactors with a slight difference. Moreover, DWDM in RZ format designed by [66] performed better than the DWDM designed by [65].

\section{3) Equalization Techniques:}

\section{a) Mechanism of Equalization}

Channel equalization deals with intersymbol interference (ISI) that is detected at the receiver. This intersymbol interference causes disruptive or unwanted channel effects that significantly degrade or, worst, renders the data or information received at the receiver unreadable. When a receiver has multiple channels, multiple symbols are being received across these multiple channels, introducing this ISI. Thus, intersymbol interference is introduced by sending more symbols than independent dimensions.

How does transmission and reception of data or information work, and how do noise and intersymbol interference be introduced or developed in a channel and then seen at the receiver? The transmitted signal and waveform in transmitting symbols are depicted by $s(t)$ and $u(t)$ respectively, while the interval of a symbol and the nth symbol is depicted by $T$ and $b_{n}$ respectively, thus the transmitted signal is shown as $b_{n} u(t-n T)$ in (2) [69], [70].

$$
\begin{gathered}
s(t)=\sum_{n} b_{n} u(t-n T) \\
r(t)=\sum_{k=-\infty}^{\infty} b_{n} v(t-n T)+n(t)
\end{gathered}
$$

On the other hand, the received signal is shown in (3), where the received signal and received waveform are depicted by $r(t)$ and $v(t)$ respectively, while the nth symbol received and intersymbol interference plus the noise are depicted by $b_{n}$ and $n(t)$ respectively [69], [70].

An equalizer is introduced or added into the system to combat these unwanted channel effects caused by intersymbol interference. Intersymbol interference causes bit rate error (BER) as it makes difficulties and errors in the recovery process of the same transmitted symbols. Thus, equalizers are implemented to retrieve the correct transmitted symbols. Equalizers are also called filters, as their primary purpose is to remove unwanted channel effects [69].

As shown in Fig. 11, a feed-forward equalizer is a passive equalizer that compensates for intersymbol interference. The feed-forward equalizer is deployed at the receiver end to create delayed versions of the input signal and implemented with multiple-tap filters along with multiple tap coefficients, which these coefficients have a net sum of one. The output signal from these taps is added back to produce a summed output, which is then forwarded to a bit slicer to mitigate preand post-cursor intersymbol interference [71].

On the other hand, an adaptive equalizer or another name for it is a decision feedback equalizer. As shown in Fig. 12, it is used to mitigate nonlinear channel effects and intersymbol interference. An adaptive equalizer is a self-learning implementation that removes unwanted attributes in the input signal and channel impairments by updating the weights to eliminate the error signal [69].

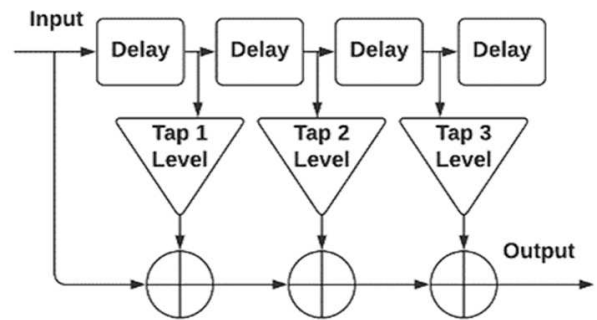

Fig. 11 Block diagram of a feed-forward equalizer with multiple taps

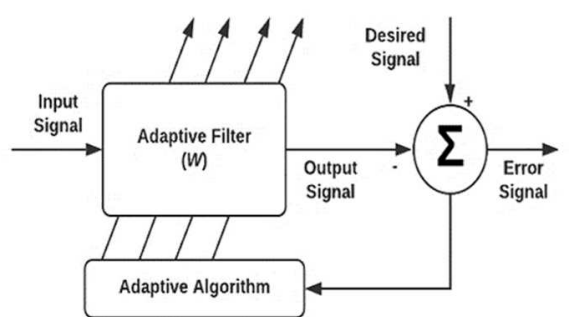

Fig. 12 Block diagram of an adaptive equalizer

In Fig. 13, the adaptive equalizer, as shown, is usually composed of multiple weights. Having multiple weights maximizes the results and minimizes the error signal. Multiple weights or feedback reduces the error signal to the minimum or acceptable levels. [69].

\section{b) Equalization in Coherent Optical Fiber Communications}

It is necessary to enhance the system by modifying only the transmitter and receiver ends or without touching or intervening with the deployed fiber cables to improve the overall performance and capacity of existing optical fiber communication systems while maintaining minimal expenses to improve the current system. Hence, most equalizers are implemented at the receiver end, and some are implemented at the transmitter. Equalizers fit this scenario where optical fiber communications improvement is only implemented at the receiver and transmitter end.

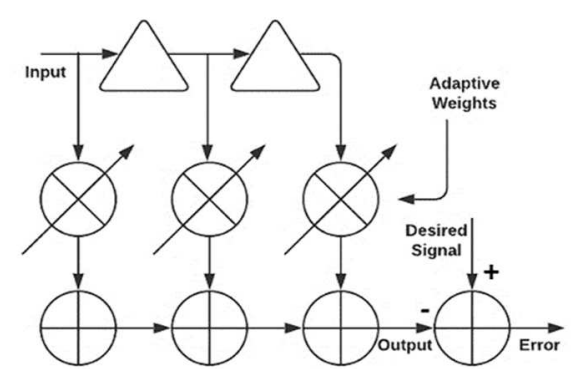

Fig. 13 Block diagram of an adaptive equalizer with multiple weights

Due to the massive amount of data being transmitted in these optical fiber channels because of coherent transmission, nonlinear channel effects were prevalent, especially intersymbol interference because of dispersion, resulting in pulse overlap between time and space. Thus, the receiver could no longer differentiate the boundaries of each pulse. Thus, it is deduced that this causes a too much bit error ratio. An equalizer is introduced to mitigate this intersymbol 
interference at the receiver end. There are two main categories in the algorithms of these equalizers, which are linear and nonlinear. The nonlinear algorithms have all the advantages to mitigate this intersymbol interference. However, the downside in implementing these nonlinear algorithms is the hardware cost and complexity. Thus, research between linear and nonlinear equalizers is thoroughly being conducted because of this compromise and attaining optimum results by either implementing linear, nonlinear, or a combination of these equalizers.

c) Comparison of Different Equalization Techniques for Coherent Optical Fiber Communications

Table 6a and Table 6b show different equalization techniques experimented with or tested over the last five years. The table's attributes comprise equalization technique, modulation scheme, data rate, different types of gain, including link budget, FEC BER-threshold, LASER type, Transmission wavelength, single-span, and overall or maximum testing distance. The authors chose a modulation scheme to experiment, which influences the proposed system's data rate and spectral efficiency. Gains, link budget, and FEC BER-Threshold were the parameters used whether the equalization technique being implemented is effective or not. In the LASER type column, the following types of lasers were used, electro-absorption-modulated laser (EML), directmodulated laser (DML), Mach-Zender modulator (MZM), external cavity laser (ECL), continuous-wave laser (CWL), distributed feedback laser (DFB), and local oscillator laser (LOL). The LASER types, transmission wavelength, singlespan distance, and overall or maximum testing distance were varying parameters to test the different equalization techniques in varying conditions or avoid bias results

TABLE V

Q-FACTOR AT VARIOUS LENGTHS

\begin{tabular}{lcccccc}
\hline \multicolumn{1}{c}{ Multiplexing } & $\begin{array}{c}\text { Pulse } \\
\text { Format }\end{array}$ & Bit rate & $\begin{array}{c}\text { Original length } \\
(\mathbf{k m})\end{array}$ & $\mathbf{Q}$ & $\mathbf{Q} \times$ Length & $\begin{array}{c}\text { Q } \times \text { Length } \\
/ \mathbf{2 2 8} \mathbf{~ k m}\end{array}$ \\
\hline OTDM [63] & RZ & $10 \mathrm{Gbps} /$ channel & 180 & 3.53 & 635.4 & 2.79 \\
DWDM [65] 1 1 & RZ & $10 \mathrm{Gbps} /$ channel & 40 & 14.60 & 584 & 2.56 \\
DWDM [66] 2 & RZ & $10 \mathrm{Gbps} /$ channel & 86 & 14.73 & 6.42 \\
DWDM [66] 3 & NRZ & $10 \mathrm{Gbps} /$ channel & 86 & 8.53 & 504 & 2.21 \\
OTDM-WDM [67] & RZ & $625 \mathrm{Mbps} /$ channel & 780 & 6.30 & 6653.4 & 29.18 \\
CO-OFDM-WDM [68] & NRZ & $12 \mathrm{Gbps} /$ channel & 200 & & 630 & 5.52 \\
\hline
\end{tabular}

TABLE VI (A)

EQUALIZATION TECHNIQUES AND SCHEMES

\begin{tabular}{|c|c|c|c|c|c|c|c|c|c|}
\hline 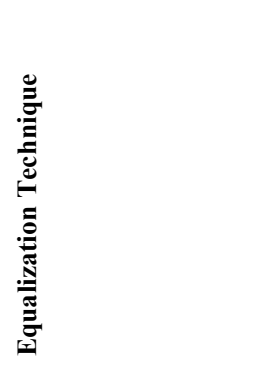 & 咅 & 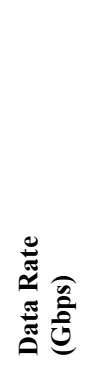 & 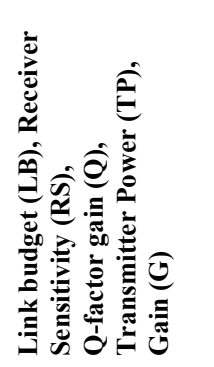 & 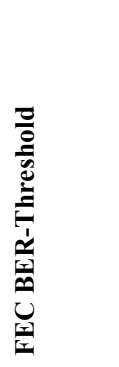 & 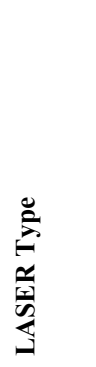 & 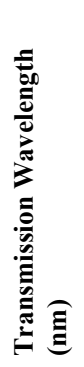 & 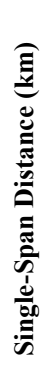 & 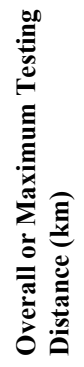 & 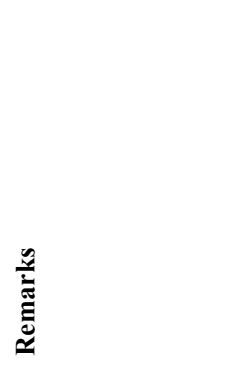 \\
\hline $\begin{array}{l}\text { 41-tap Feed- } \\
\text { Forward } \\
\text { Equalization }+ \\
\text { Maximum- } \\
\text { likelihood Sequence } \\
\text { Estimation [72] }\end{array}$ & OOK & 50 & $31.8 \mathrm{~dB}-(\mathrm{LB})$ & $\begin{array}{l}2 \\
\times 10^{-2}\end{array}$ & EML & 1342 & 20 & 20 & $\begin{array}{l}\text { The proposed } \\
\text { equalization } \\
\text { technique } \\
\text { achieved a } 1 \mathrm{~dB} \\
\text { improvement in } \\
\text { FEC BER- } \\
\text { threshold and } \\
\text { attaining a } 31.8 \\
\text { dB Link Budget }\end{array}$ \\
\hline $\begin{array}{l}\text { 32-tap Feed- } \\
\text { Forward } \\
\text { Equalization [73] }\end{array}$ & OOK & 50 & $34.8 \mathrm{~dB}-(\mathrm{LB})$ & $\begin{array}{l}2 \\
\times 10^{-2}\end{array}$ & DML & 1342 & 20 & 20 & $\begin{array}{l}\text { The proposed } \\
\text { equalization } \\
\text { technique } \\
\text { achieved a } 34.8 \\
\text { dB Link Budget } \\
\text { and attaining a - } \\
29.8 \mathrm{dBm} \\
\text { receiver } \\
\text { sensitivity }\end{array}$ \\
\hline $\begin{array}{l}\text { Feed-forward } \\
\text { equalization }+ \\
\text { Decision Feedback } \\
\text { Equalizer }[74]\end{array}$ & OOK & 40 & $25 \mathrm{~dB}-(\mathrm{LB})$ & $10^{-3}$ & MZM & 1550 & 20 & 20 & $\begin{array}{l}\text { The proposed } \\
\text { equalization } \\
\text { technique } \\
\text { achieved a } 25 \mathrm{~dB} \\
\text { Link Budget }\end{array}$ \\
\hline
\end{tabular}




\begin{tabular}{|c|c|c|c|c|c|c|c|c|c|}
\hline $\begin{array}{l}\text { Maximum- } \\
\text { likelihood Sequence } \\
\text { Estimation [75] }\end{array}$ & OOK & 25 & $\begin{array}{l}-24.06 \mathrm{dBm}- \\
(\mathrm{RS})\end{array}$ & $10^{-3}$ & EML & 1545 & 25 & 25 & $\begin{array}{l}\text { Maximum- } \\
\text { likelihood } \\
\text { Sequence }\end{array}$ \\
\hline $\begin{array}{l}\text { 5-tap Feed-Forward } \\
\text { Equalization }+1- \\
\text { tap Decision } \\
\text { Feedback Equalizer } \\
{[75]}\end{array}$ & $\mathrm{OOK}$ & 25 & $\begin{array}{l}-18.68 \mathrm{dBm}- \\
\text { (RS) }\end{array}$ & $10^{-3}$ & EML & 1545 & 25 & 25 & $\begin{array}{l}\text { Estimation } \\
\text { achieved the best } \\
\text { performance } \\
\text { compared to } \\
\text { other proposed }\end{array}$ \\
\hline $\begin{array}{l}\text { 15-tap Feed- } \\
\text { Forward } \\
\text { Equalization }+1- \\
\text { tap Decision } \\
\text { Feedback Equalizer } \\
\text { [75] }\end{array}$ & OOK & 25 & $\begin{array}{l}-21.84 \mathrm{dBm}- \\
\text { (RS) }\end{array}$ & $10^{-3}$ & EML & 1545 & 25 & 25 & $\begin{array}{l}\text { equalization } \\
\text { techniques as it } \\
\text { achieves the best } \\
\text { receiver } \\
\text { sensitivity of - } \\
24.06 \mathrm{dBm}\end{array}$ \\
\hline $\begin{array}{l}\text { 13-tap Feed- } \\
\text { Forward } \\
\text { Equalization }+7- \\
\text { tap Decision } \\
\text { Feedback Equalizer } \\
\text { [75] }\end{array}$ & OOK & 25 & $\begin{array}{l}-22.83 \mathrm{dBm}- \\
(\mathrm{RS})\end{array}$ & $10^{-3}$ & EML & 1545 & 25 & 25 & \\
\hline Bayesian Filter [76] & 64-QAM & 56 & $3 \mathrm{~dB}-(\mathrm{Q})$ & $\begin{array}{l}4 \\
\times 10^{-2}\end{array}$ & - & - & 250 & 800 & $\begin{array}{l}3 \mathrm{~dB} \text { gain is } \\
\text { achieved against } \\
\text { inter-channel } \\
\text { nonlinear effects }\end{array}$ \\
\hline $\begin{array}{l}\text { Newton-Based } \\
\text { Support Vector } \\
\text { Machine Nonlinear } \\
\text { Equalizer [77] }\end{array}$ & 16-QAM & 40 & $3.5 \mathrm{~dB}-(\mathrm{G})$ & $10^{-3}$ & ECL & 1550.2 & 100 & 2000 & $\begin{array}{l}3.5 \mathrm{~dB} \text { power } \\
\text { gain was } \\
\text { achieved } \\
\text { compared to } \\
\text { Linear } \\
\text { Equalization }\end{array}$ \\
\hline $\begin{array}{l}\text { Fully Blind } \\
\text { Density-Centroid } \\
\text { Tracking Equalizer } \\
\text { [78] }\end{array}$ & 64-QAM & 75 & $2 \mathrm{~dB}-(\mathrm{G})$ & $10^{-3}$ & ECL & - & 80 & 80 & $\begin{array}{l}2 \text { dB overall } \\
\text { improvement } \\
\text { compared to } \\
\text { back-to-back } \\
\text { signal while } \\
\text { maintaining low } \\
\text { system } \\
\text { complexity }\end{array}$ \\
\hline $\begin{array}{l}\text { Inverse } \\
\text { Hammerstein } \\
\text { Nonlinear Equalizer } \\
{[79]}\end{array}$ & QPSK & 40 & $\begin{array}{l}1 \mathrm{dBm}>\mathrm{LE}- \\
(\mathrm{G})\end{array}$ & $10^{-3}$ & MZM & 1550 & 120 & 120 & $\begin{array}{l}\text { An increase of } \\
\text { around } 5 \mathrm{~km} \\
\text { transmission } \\
\text { distance was } \\
\text { achieved }\end{array}$ \\
\hline $\begin{array}{l}\text { Radial Basis } \\
\text { Function Neural } \\
\text { Network Nonlinear } \\
\text { Equalizer }[80]\end{array}$ & 16-QAM & 80 & $\begin{array}{l}2.5 \mathrm{~dB}>\mathrm{ANN}- \\
\mathrm{NLE}-(\mathrm{Q})\end{array}$ & $10^{-3}$ & MZM & - & 100 & 1200 & $\begin{array}{l}\text { The proposed } \\
\text { equalization } \\
\text { technique } \\
\text { achieves } 2.5 \mathrm{~dB} \\
\text { gain more } \\
\text { compared to } \\
\text { ANN-based } \\
\text { Nonlinear } \\
\text { Equalizer }\end{array}$ \\
\hline $\begin{array}{l}\text { Support Vector } \\
\text { Machine-based } \\
\text { Nonlinear Equalizer } \\
{[81]}\end{array}$ & 16-QAM & 40 & $\begin{array}{l}1 \mathrm{~dB}>\mathrm{ANN}- \\
\mathrm{NLE}-(\mathrm{Q})\end{array}$ & $10^{-3}$ & MZM & - & 100 & 400 & $\begin{array}{l}\text { The proposed } \\
\text { equalization } \\
\text { technique } \\
\text { achieves a } 1 \mathrm{~dB} \\
\text { penalty } \\
\text { improvement } \\
\text { compared to } \\
\text { ANN-based NLE }\end{array}$ \\
\hline $\begin{array}{l}\text { Digital Back- } \\
\text { Propagation } \\
\text { Equalizer [82] }\end{array}$ & 64-QAM & 210 & $0.4 \mathrm{~dB}-(\mathrm{Q})$ & $\begin{array}{l}3.8 \\
\times 10^{-3}\end{array}$ & ECL & - & 160 & 160 & $\begin{array}{l}\text { The proposed } \\
\text { equalization } \\
\text { technique } \\
\text { mitigated around } \\
60 \% \text { of nonlinear } \\
\text { noise resulting in } \\
\text { a } 0.4 \mathrm{~dB} \text { gain }\end{array}$ \\
\hline
\end{tabular}




\begin{tabular}{|c|c|c|c|c|c|c|c|c|c|}
\hline $\begin{array}{l}\text { Support Vector } \\
\text { Machine Nonlinear } \\
\text { Equalizer [83] }\end{array}$ & 16-QAM & 100 & $\begin{array}{l}1.11 \mathrm{~dB}> \\
\text { Volterra-NLE, } \\
1.17 \mathrm{~dB}>\mathrm{W}-\mathrm{H}- \\
\mathrm{NLE}, 1.56 \mathrm{~dB}> \\
\mathrm{LE}-(\mathrm{Q})\end{array}$ & $10^{-4}$ & CWL & 1550 & 80 & 400 & $\begin{array}{l}\text { The proposed } \\
\text { equalization } \\
\text { technique } \\
\text { outperforms the } \\
\text { other } \\
\text { equalizations } \\
\text { such as V-NLE, } \\
\text { W-H-NLE, and } \\
\text { LE }\end{array}$ \\
\hline $\begin{array}{l}\text { Functional-Link } \\
\text { Neural Network- } \\
\text { based Equalizer } \\
{[10]}\end{array}$ & 16-QAM & 100 & $7 \mathrm{dBm}-(\mathrm{TP})$ & $\begin{array}{l}3.8 \\
\times 10^{-3}\end{array}$ & ECL & 1550 & 50 & 1000 & $\begin{array}{l}\text { The proposed } \\
\text { equalization } \\
\text { technique } \\
\text { achieved a } 7 \% \\
\text { improvement in } \\
\text { FEC BER- } \\
\text { threshold }\end{array}$ \\
\hline
\end{tabular}

\section{RESULTS AND DisCUSSIONS}

\section{A. Coding Techniques}

Table 2 in Section 2 provides a comprehensive survey about proposed and implemented coding schemes for higher speed in coherent optical fiber communication. The listed codes are compared based on their decision or decoding methods and their main advantages. It can be observed that the majority of the schemes are targeting lower complexity of decoding circuits, which provides lower latency and costs. The redundancies or $\mathrm{OH}$ are also considered, given that a higher $\mathrm{OH}$ enhances robustness for longer transmissions. Mitigating error floors are also considered by other schemes that enhance the performance of the code.

Channel coding plays a vital role in an efficient and errorfree transmission at higher speeds. This survey provides a valuable review of such codes tested, implemented, or simulated for advancement, standardization, and interoperability of coherent optics. FEC schemes are proprietary to vendors, and FEC schemes' standardization and interoperability remain a challenge to this day. Different FEC can be combined with other schemes such as Coded modulation (CM) and probabilistic shaping [30], and application in the optical domain also brings a new perspective for future optical networks [61]. The simulation of schemes under the same parameters and other schemes that are not yet fully implemented on hardware is recommended for future works.

\section{B. Multiplexing Techniques}

Section 2 shows some multiplexing techniques gathered from the literature of [63] and [65]-[68]. The common parameters from each literature were taken to have a comparison among the techniques. The techniques' bit rate was compared. As shown in Table 5, CO-OFDM-WDM designed by [68] has the highest bit rate per channel of 12 Gbps. The purpose of having three DWDM presented in table 3 is to see the difference between NRZ and RZ format. Two DWDM designed by [65] and [66] are in the same RZ format but with different power sources and lengths, while the last DWDM, designed by [66], is in NRZ format. By comparison to both DWDM designed by [66] and have the same parameter values, the NRZ format needs higher source power than DWDM in RZ format; in this case, DWDM in NRZ format needs $7 \mathrm{dBm}$ to achieve BER of $8.89 \times 10^{-10}$. Also, both DWDM in RZ format have close values of BER and Qfactors.

The performance of the optical fiber system was compared using the Q-factors of each technique. Q-factors and the length were multiplied and divided by an average of the total length to obtain a base comparison. In general, the formula used for comparison is $\mathrm{Q}$ multiplied by its length divided by the average length ( $\mathrm{Q} x$ Length /Average Length). Table 5 shows the results of $\mathrm{Q}$ of multiplexing techniques in uniform length. CO-OFDM-WDM has the highest Q-factor but the lowest in terms of bit rate.

\section{Equalization Techniques}

As shown in Table 6a and Table 6b, a comprehensive survey of equalization techniques and algorithms experiments and tests conducted over the last five years shows that many studies support vector machine or supervised machine learning. The equalizer is being utilized to lower the BER, thus lowering the receiver sensitivity at the same time. By lowering the receiver sensitivity, one can lower the launched optical power or increase the overall link budget. By successfully increasing the link budget, one can increase the fiber optic channel's transmission distance without the need for a repeater or amplifier.

Based on Table $6 \mathrm{a}$ and Table $6 \mathrm{~b}$, the furthest testing performed without a repeater or amplifier was at $250 \mathrm{~km}$, and the maximum testing distance was at $3200 \mathrm{~km}$. These results show that one could transmit data at a distance of $3200 \mathrm{~km}$ using around nine repeaters or amplifiers. However, even if implementing equalizers significantly improves the fiber optics channel's overall system, the end utilization must also consider its hardware implementation cost and complexity. Thus, most of these studies revolve around finding the best equalization technique and algorithm that yields optimum overall performance, such as mitigating fiber channel optic channel dispersions while attaining low hardware cost and complexity. The latest work, such as those in [90]-[93], do not provide pertinent information to be included in the survey but can be considered in the future. 


\begin{tabular}{|c|c|c|c|c|c|c|c|c|c|}
\hline 苞 & 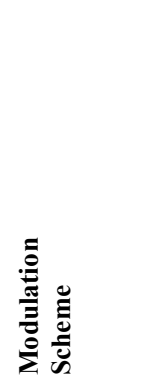 & 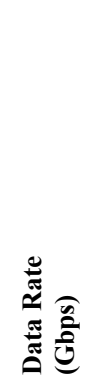 & 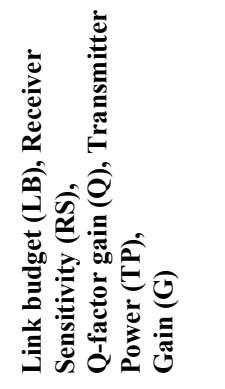 & 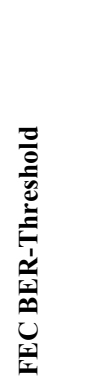 & 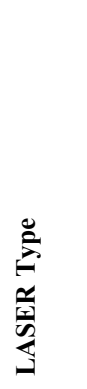 & 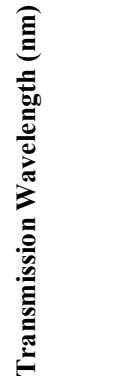 & 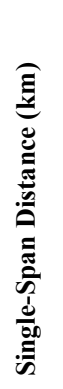 & 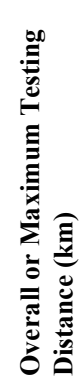 & 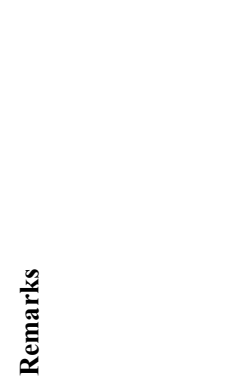 \\
\hline $\begin{array}{l}\text { Fuzzy-logic-based } \\
\text { Nonlinear Equalizer } \\
{[84]}\end{array}$ & 16-QAM & 46 & $1.8 \mathrm{~dB}-(\mathrm{Q})$ & $10^{-6}$ & DFB & 1550.2 & 100 & 2000 & $\begin{array}{l}\text { Fuzzy-logic } \\
\text { always has the } \\
\text { best performance } \\
\text { compared to the }\end{array}$ \\
\hline $\begin{array}{l}\text { Hierarchical Clustering } \\
\text { Nonlinear Equalizer } \\
{[84]}\end{array}$ & 16-QAM & 46 & $-1.2 \mathrm{~dB}-(\mathrm{Q})$ & $10^{-6}$ & DFB & 1550.2 & 100 & 2000 & $\begin{array}{l}\text { other algorithms } \\
\text { while maintaining } \\
\text { low power }\end{array}$ \\
\hline $\begin{array}{l}\text { K-means Clustering } \\
\text { Nonlinear Equalizer } \\
{[84]}\end{array}$ & 16-QAM & 46 & $-0.2 \mathrm{~dB}-(\mathrm{Q})$ & $10^{-6}$ & DFB & 1550.2 & 100 & 2000 & $\begin{array}{l}\text { consumption and } \\
\text { lower system } \\
\text { complexity }\end{array}$ \\
\hline $\begin{array}{l}\text { Artificial Neural } \\
\text { Network-based } \\
\text { Nonlinear Equalizer } \\
{[84]}\end{array}$ & 16-QAM & 46 & $0.7 \mathrm{~dB}-(\mathrm{Q})$ & $10^{-6}$ & DFB & 1550.2 & 100 & 2000 & \\
\hline $\begin{array}{l}\text { Fast-Newton Support } \\
\text { Vector Machine } \\
\text { Nonlinear Equalizer } \\
{[84]}\end{array}$ & 16-QAM & 46 & $0.7 \mathrm{~dB}-(\mathrm{Q})$ & $10^{-6}$ & DFB & 1550.2 & 100 & 2000 & \\
\hline $\begin{array}{l}\text { Inverse Volterra-series } \\
\text { transfer function } \\
\text { Nonlinear Equalizer } \\
{[84]}\end{array}$ & 16-QAM & 46 & $0.7 \mathrm{~dB}-(\mathrm{Q})$ & $10^{-6}$ & DFB & 1550.2 & 100 & 2000 & \\
\hline $\begin{array}{l}\text { 15-tap Finite Impulse } \\
\text { Response Filter }+ \\
\text { Constant Modulus } \\
\text { Algorithm-based } \\
\text { Equalizer [85] }\end{array}$ & $\begin{array}{l}\text { Sinusoidal } \\
\text {-shaped } \frac{\pi}{4} \\
\text { Quadratur } \\
\text { e Phase- } \\
\text { shift } \\
\text { Keying } \\
\text { (QPSK) }\end{array}$ & 20 & $\begin{array}{l}-44.7 \mathrm{dBm}- \\
(\mathrm{RS})\end{array}$ & $10^{-3}$ & DML & 1552.68 & 40 & 40 & $\begin{array}{l}\text { Optimum receiver } \\
\text { sensitivity was } \\
\text { achieved; } \\
\text { however, } \\
\text { convergence time } \\
\text { takes about } 40 \\
\text { seconds }\end{array}$ \\
\hline $\begin{array}{l}\text { 1-tap Butterfly Finite } \\
\text { Impulse Response Filter } \\
\text { + N-tap Real-valued } \\
\text { Finite Impulse } \\
\text { Response Filter + 3-tap } \\
\text { Post Finite Impulse } \\
\text { Response Filter [86] }\end{array}$ & $\begin{array}{l}\text { Polarizati } \\
\text { on } \\
\text { Division } \\
\text { Multiplexi } \\
\text { ng (PDM) } \\
\text { 16-QAM }\end{array}$ & 448 & $-24 \mathrm{dBm}-(\mathrm{RS})$ & $\begin{array}{l}3.8 \\
\times 10^{-3}\end{array}$ & - & - & 0.6 & 8 & $\begin{array}{l}\text { The proposed } \\
\text { advanced } \\
\text { equalization } \\
\text { technique had } \\
\text { achieved an } \\
\text { overall 1-dB } \\
\text { receiver } \\
\text { sensitivity penalty }\end{array}$ \\
\hline $\begin{array}{l}\text { Maximum-Likelihood } \\
\text { Recursive Least- } \\
\text { Squares-based Support } \\
\text { Vector Machine Blind } \\
\text { Nonlinear Equalizer } \\
\text { [87] }\end{array}$ & 16-QAM & 41 & $\begin{array}{l}1.7 \mathrm{~dB}> \\
\text { Volterra-based } \\
\text { NLE }-(\mathrm{Q})\end{array}$ & $10^{-3}$ & ECL & 1550.2 & 100 & 3200 & $\begin{array}{l}\text { The proposed } \\
\text { equalization } \\
\text { technique has } \\
\text { optimum results if } \\
\text { implemented in a } \\
\text { high number of } \\
\text { subcarriers } \\
\text { because it can } \\
\text { mitigate inter- } \\
\text { subcarrier four- } \\
\text { wave mixing }\end{array}$ \\
\hline
\end{tabular}




\begin{tabular}{|c|c|c|c|c|c|c|c|c|c|}
\hline $\begin{array}{l}\text { Least Mean Square } \\
\text { Adaptive Equalizer [88] }\end{array}$ & $\begin{array}{l}\text { PDM } \\
\text { QPSK }\end{array}$ & 10 & $13 \mathrm{dBm}-(\mathrm{TP})$ & $\begin{array}{l}3.8 \\
\times 10^{-3}\end{array}$ & LOL & - & 60 & 120 & $\begin{array}{l}\text { The optimum } \\
\text { performance was } \\
\text { achieved by } \\
\text { implementing } \\
\text { more than } 2 \text { Mrad } \\
\text { per second } \\
\text { polarization speed } \\
\text { to improve system } \\
\text { performance and } \\
\text { tackle high } \\
\text { polarization } \\
\text { rotation issues }\end{array}$ \\
\hline $\begin{array}{l}\text { Volterra-based } \\
\text { Nonlinear Equalizer } \\
\text { [89] }\end{array}$ & $\begin{array}{l}\text { Dual } \\
\text { Polarizati } \\
\text { on 16- } \\
\text { QAM }\end{array}$ & 256 & $1.8 \mathrm{~dB}-(\mathrm{Q})$ & $\begin{array}{l}2.5 \\
\times 10^{-2}\end{array}$ & - & - & 75 & 1570 & $\begin{array}{l}\text { The proposed } \\
\text { equalization } \\
\text { technique } \\
\text { achieved a } \\
\text { transmission } \\
\text { distance of } 1570 \\
\text { km or a } 48 \% \\
\text { increase } \\
\text { compared to } \\
\text { Linear } \\
\text { Equalization }\end{array}$ \\
\hline $\begin{array}{l}\text { Multiple Layers } \\
\text { Perceptron Artificial } \\
\text { Neural Network-based } \\
\text { Nonlinear Equalizer } \\
{[11]}\end{array}$ & 16-QAM & 40 & $1.4 \mathrm{~dB}-(\mathrm{Q})$ & $10^{-3}$ & - & - & 100 & 600 & $\begin{array}{l}1.4 \mathrm{~dB} \text { gain was } \\
\text { achieved for a } 600 \\
\mathrm{~km} \text { transmission } \\
\text { distance }\end{array}$ \\
\hline
\end{tabular}

\section{CONCLUSIONS}

The authors were able to gather literature related to coding schemes and develop a survey table. The survey was able to show each advantage of the FEC schemes presented. The coding schemes were also compared based on their decoding methods. The majority of the schemes showed lower complexity of decoding circuits; thus, these schemes provide lower latency and cost. The redundancy was also considered; consequently, higher $\mathrm{OH}$ enhances robustness for longer transmission.

The author was able to present and discuss some multiplexing techniques gathered from different works of literature. Among the techniques, CO-OFDM-WDM was designed with a higher bit rate per channel. Three DWDM techniques were presented; in particular, two DWDM is in RZ format and one in DWDM in NRZ format. In summary, the RZ format requires lesser power than NRZ; likewise, the RZ format has a lower BER than RZ.

Based on the results in Table 5, the designed OTDM-WDM by [67] has the highest Q-factor relative to $228 \mathrm{~km}$ among the gathered techniques. However, overall, OTDM-WDM has a lower bit rate than the designed CO-OFDM-WDM by [68]; besides, CO-OFDM-WDM shows a higher Q-factor compared to the other two multiplexing techniques (OTDM and DWDM).

Finally, the authors gathered from different literature that contains conducted tests and experiments related to equalization techniques. As discussed, an equalizer is used to mitigate unwanted channel effects to lower the BER. Thus, by lowering the BER, a lower receiver sensitivity would identify information or symbols in a multiple independent dimension. It was observed that increasing the launched optical power and lowering the receiver sensitivity results in increasing the overall link budget.
Moreover, by increasing the link budget, an increase in transmission distance is possible without a repeater or amplifier. Table $6 \mathrm{a}$ and Table $6 \mathrm{~b}$ showed that the maximum reach is $250 \mathrm{~km}$; meanwhile, with around nine repeaters and amplifiers, the maximum distance can reach $3200 \mathrm{~km}$. Furthermore, tradeoffs between system improvement and cost must be considered when implementing an equalizer because most of the equalization techniques and algorithms gathered yield an optimum overall performance increase. However, they significantly vary in hardware complexity and cost. For further studies, computation of hardware cost and complexity must be evaluated against the top equalization technologies while including a comparison of just simply adding a repeater or amplifier and deploying a new fiber cable, whichever yields the optimum results in terms of data rate, hardware cost, and complexity. The authors propose simulations to compare the above schemes reasonably as future work.

\section{ACKNOWLEDGMENT}

The Gokongwei Brothers Foundation is acknowledged for supporting this work.

\section{REFERENCES}

[1] L. N. Binh, Optical fiber communication systems with Matlab and Simulink models; 2nd ed. Hoboken, NJ: CRC Press, 2014 [Online]. Available: https://cds.cern.ch/record/2024949.

[2] K. Kikuchi, "Fundamentals of Coherent Optical Fiber Communications," Journal of Lightwave Technology, vol. 34, no. 1, pp. 157-179, Jan. 2016, doi: 10.1109/JLT.2015.2463719.

[3] X. Liu, "Evolution of Fiber-Optic Transmission and Networking toward the 5G Era," iScience, vol. 22, pp. 489-506, Dec. 2019, doi: 10.1016/j.isci.2019.11.026.

[4] D. A. Morero, M. A. Castrillón, A. Aguirre, M. R. Hueda, and O. E. Agazzi, "Design Tradeoffs and Challenges in Practical Coherent Optical Transceiver Implementations," Journal of Lightwave Technology, vol. 34, no. 1, pp. 121-136, Jan. 2016, doi: 10.1109/JLT.2015.2470114. 
[5] F. Fresi et al., "Advances in optical technologies and techniques for high capacity communications," IEEE/OSA Journal of Optical Communications and Networking, vol. 9, no. 4, pp. C54-C64, Apr. 2017, doi: 10.1364/JOCN.9.000C54.

[6] A. Amari, O. A. Dobre, R. Venkatesan, O. S. S. Kumar, P. Ciblat, and Y. Jaouën, "A Survey on Fiber Nonlinearity Compensation for 400 $\mathrm{Gb} / \mathrm{s}$ and Beyond Optical Communication Systems," IEEE Communications Surveys Tutorials, vol. 19, no. 4, pp. 3097-3113, Fourthquarter 2017, doi: 10.1109/COMST.2017.2719958.

[7] Q. Tan, Z. Wang, A. Yang, and P. Guo, "Coherent Optical Sampling Based Method for Monitoring Optical Signal to Noise Ratio of High Speed Optical Fiber Communication Systems," in 2019 7th International Conference on Information, Communication and Networks (ICICN), 2019, pp. 135-139, doi: 10.1109/ICICN.2019.8834945.

[8] I. Tomkos, A. Tolmachev, A. Agmon, M. Meltsin, T. Nikas, and M. Nazarathy, "Low-Cost/Power Coherent Transceivers for IntraDatacenter Interconnections and 5G Fronthaul Links," in 2019 21st International Conference on Transparent Optical Networks (ICTON), 2019, pp. 1-5, doi: 10.1109/ICTON.2019.8840195.

[9] C. Jing, X. Tang, X. Zhang, L. Xi, and W. Zhang, "Time domain synchronous OFDM system for optical fiber communications," China Communications, vol. 16, no. 9, pp. 155-164, Sep. 2019, doi: 10.23919/JCC.2019.09.011.

[10] J. Zhang et al., "Functional-Link Neural Network for Nonlinear Equalizer in Coherent Optical Fiber Communications," IEEE Access, vol. 7, pp. 149900-149907, 2019, doi: 10.1109/ACCESS.2019.2947278

[11] H. Zhang, Z. Yu, L. Shu, Z. Wan, Y. Zhao, and K. Xu, "Fiber Nonlinearity Equalizer using MLP-ANN for Coherent Optical OFDM," in 2019 18th International Conference on Optical Communications and Networks (ICOCN), 2019, pp. 1-3, doi: 10.1109/ICOCN.2019.8934433.

[12] F. Musumeci et al., "An Overview on Application of Machine Learning Techniques in Optical Networks," IEEE Communications Surveys Tutorials, vol. 21, no. 2, pp. 1383-1408, Secondquarter 2019, doi: 10.1109/COMST.2018.2880039.

[13] A. Tychopoulos, O. Koufopavlou, and I. Tomkos, "FEC in optical communications - A tutorial overview on the evolution of architectures and the future prospects of outband and inband FEC for optical communications," IEEE Circuits and Devices Magazine, vol. 22, no. 6, pp. 79-86, Nov. 2006, doi: 10.1109/MCD.2006.307281

[14] G. Tzimpragos, C. Kachris, I. B. Djordjevic, M. Cvijetic, D. Soudris, and I. Tomkos, "A Survey on FEC Codes for $100 \mathrm{G}$ and Beyond Optical Networks," IEEE Communications Surveys Tutorials, vol. 18 , no. 1, pp. 209-221, Firstquarter 2016, doi: 10.1109/COMST.2014.2361754.

[15] A. Leven and L. Schmalen, "Status and Recent Advances on Forward Error Correction Technologies for Lightwave Systems," Journal of Lightwave Technology, vol. 32, no. 16, pp. 2735-2750, Aug. 2014, doi: 10.1109/JLT.2014.2319896

[16] I. B. Djordjevic, "On Advanced FEC and Coded Modulation for UltraHigh-Speed Optical Transmission," IEEE Communications Surveys Tutorials, vol. 18, no. 3, pp. 1920-1951, thirdquarter 2016, doi: 10.1109/COMST.2016.2536726.

[17] L. Beygi, E. Agrell, J. M. Kahn, and M. Karlsson, "Coded Modulation for Fiber-Optic Networks: Toward better tradeoff between signal processing complexity and optical transparent reach," IEEE Signal Processing Magazine, vol. 31, no. 2, pp. 93-103, Mar. 2014, doi: 10.1109/MSP.2013.2290805.

[18] D. Wang, S. Zhang, and Q. Li, "WDM transmission system based on coherent optical OFDM and its performance analysis," in 2019 IEEE $3 r$ Information Technology, Networking, Electronic and Automation Control Conference (ITNEC), 2019, pp. 2157-2161, doi: 10.1109/ITNEC.2019.8729044.

[19] S. Pradhan, B. Patnaik, and R. Panigrahy, "Hybrid Multiplexing (OTDM/WDM) Technique for Fiber Optic Communication," in 2018 IEEE 5th International Conference on Engineering Technologies and Applied Sciences (ICETAS), 2018, pp. 1-5.

[20] T. Kaur and G. Soni, "Performance analysis of OTDM link at $40 \mathrm{Gbps,"}$ in 2015 International Conference on Green Computing and Internet of Things (ICGCIoT), 2015, pp. 240-243.

[21] E. Ciaramella, F. Bottoni, R. Corsini, M. Presi, and M. Artiglia, "Simple and effective solutions for low-cost coherent WDM-PON," in 2015 International Conference on Photonics in Switching (PS), 2015, pp. 271-272, doi: 10.1109/PS.2015.7329023.
[22] J. Yu et al., “400G/Channel 50-GHz WDM Coherent Transmission: PS 64QAM Versus Hybrid 32/64QAM," in 2019 Optical Fiber Communications Conference and Exhibition (OFC), 2019, pp. 1-3.

[23] J. M. Senior and M. Y. Jamro, Optical fiber communications: principles and practice. Pearson Education, 2009.

[24] A. Israr, M. Junaid, and A. Israr, "Performance Analysis of Advance Optical Modulation Formats for GPON System," in 2015 13th International Conference on Frontiers of Information Technology (FIT), 2015, pp. 77-80, doi: 10.1109/FIT.2015.11.

[25] K. Chen, Y. Yu, S. Liaw, Z. Lee, Y. Lee, and N. Goto, "BER and Q factor evaluation of narrow-linewidth fiber ring laser," in 2016 IEEE 6th International Conference on Photonics (ICP), 2016, pp. 1-3, doi: 10.1109/ICP.2016.7510045

[26] C. E. Shannon, "A mathematical theory of communication," Bell system technical journal, vol. 27, no. 3, pp. 379-423, 1948.

[27] F. Buchali, G. Böcherer, W. Idler, L. Schmalen, P. Schulte, and F. Steiner, "Experimental demonstration of capacity increase and rateadaptation by probabilistically shaped 64-QAM," in 2015 European Conference on Optical Communication (ECOC), 2015, pp. 1-3, doi: 10.1109/ECOC.2015.7341688.

[28] R. Gallager, "Low-density parity-check codes," IRE Transactions on Information Theory, vol. 8, no. 1, pp. 21-28, Jan. 1962, doi: 10.1109/TIT.1962.1057683.

[29] M. Franceschini, G. Ferrari, and R. Raheli, "Does the Performance of LDPC Codes Depend on the Channel?," IEEE Transactions on Communications, vol. 54, no. 12, pp. 2129-2132, Dec. 2006, doi: 10.1109/TCOMM.2006.885042.

[30] G. Böcherer, P. Schulte, and F. Steiner, "Probabilistic Shaping and Forward Error Correction for Fiber-Optic Communication Systems," Journal of Lightwave Technology, vol. 37, no. 2, pp. 230-244, Jan. 2019, doi: 10.1109/JLT.2019.2895770.

[31] J. Cho and P. J. Winzer, "Probabilistic Constellation Shaping for Optical Fiber Communications," Journal of Lightwave Technology, vol. 37, no. 6, pp. 1590-1607, Mar. 2019, doi: 10.1109/JLT.2019.2898855.

[32] K. Lee, H. Kang, J. Park, and H. Lee, "100GB/S two-iteration concatenated $\mathrm{BCH}$ decoder architecture for optical communications," in 2010 IEEE Workshop On Signal Processing Systems, 2010, pp. 404-409, doi: 10.1109/SIPS.2010.5624879.

[33] B. Li, K. J. Larsen, D. Zibar, and I. T. Monroy, "Over 10 dB net coding gain based on $20 \%$ overhead hard decision forward error correction in $100 \mathrm{G}$ optical communication systems," in 201137 th European Conference and Exhibition on Optical Communication, 2011, pp. 1-3.

[34] D. Chang et al., "LDPC convolutional codes using layered decoding algorithm for high speed coherent optical transmission," in OFC/NFOEC, 2012, pp. 1-3.

[35] T. Mizuochi et al., "Experimental Demonstration of Concatenated LDPC and RS Codes by FPGAs Emulation," IEEE Photonics Technology Letters, vol. 21, no. 18, pp. 1302-1304, Sep. 2009, doi: 10.1109/LPT.2009.2025867.

[36] N. Kamiya and S. Shioiri, "Concatenated QC-LDPC and SPC codes for 100 Gbps ultra long-haul optical transmission systems," in 2010 Conference on Optical Fiber Communication (OFC/NFOEC), collocated National Fiber Optic Engineers Conference, 2010, pp. 13, doi: 10.1364/OFC.2010.OThL2.

[37] Deyuan Chang et al., "FPGA verification of a single QC-LDPC code for $100 \mathrm{~Gb} / \mathrm{s}$ optical systems without error floor down to BER of 10-15," in 2011 Optical Fiber Communication Conference and Exposition and the National Fiber Optic Engineers Conference, 2011, pp. 1-3.

[38] D. A. Morero, M. A. Castrillon, F. A. Ramos, T. A. Goette, O. E. Agazzi, and M. R. Hueda, "Non-Concatenated FEC Codes for UltraHigh Speed Optical Transport Networks," in 2011 IEEE Global Telecommunications Conference - GLOBECOM 2011, 2011, pp. 1-5, doi: 10.1109/GLOCOM.2011.6133616.

[39] K. Sugihara et al., "A spatially-coupled type LDPC Code with an NCG of $12 \mathrm{~dB}$ for optical transmission beyond $100 \mathrm{~Gb} / \mathrm{s}$," in 2013 Optical Fiber Communication Conference and Exposition and the National Fiber Optic Engineers Conference (OFC/NFOEC), 2013, pp. 1-3, doi: 10.1364/OFC.2013.OM2B 4.

[40] C. Choi, H. Lee, N. Kaneda, and Y. Chen, "Concatenated non-binary LDPC and HD-FEC codes for $100 \mathrm{~Gb} / \mathrm{s}$ optical transport systems," in 2012 IEEE International Symposium on Circuits and Systems (ISCAS), 2012, pp. 1783-1786, doi: 10.1109/ISCAS.2012.6271611.

[41] T. Mizuochi et al., "Evolution and status of forward error correction," in OFC/NFOEC, 2012, pp. 1-3. 
[42] K. Onohara et al., "Soft-Decision-Based Forward Error Correction for $100 \mathrm{~Gb} / \mathrm{s}$ Transport Systems," IEEE Journal of Selected Topics in Quantum Electronics, vol. 16, no. 5, pp. 1258-1267, Sep. 2010, doi: 10.1109/JSTQE.2010.2040809.

[43] B. P. Smith, A. Farhood, A. Hunt, F. R. Kschischang, and J. Lodge, "Staircase Codes: FEC for $100 \mathrm{~Gb} / \mathrm{s}$ OTN," Journal of Lightwave Technology, vol. 30, no. 1, pp. 110-117, Jan. 2012, doi: 10.1109/JLT.2011.2175479.

[44] I. B. Djordjevic, L. Xu, and T. Wang, "Multidimensional turbo product and generalized LDPC codes with component RS codes suitable for use in beyond $100 \mathrm{~Gb} / \mathrm{s}$ optical transmission," in 2009 9th International Conference on Telecommunication in Modern Satellite, Cable, and Broadcasting Services, 2009, pp. 402-405, doi 10.1109/TELSKS.2009.5339509.

[45] Z. Wang, "Super-FEC Codes for 40/100 Gbps Networking," IEEE Communications Letters, vol. 16, no. 12, pp. 2056-2059, Dec. 2012, doi: 10.1109/LCOMM.2012.112012.122083.

[46] M. Scholten, T. Coe, and J. Dillard, "Continuously-interleaved BCH (CI-BCH) FEC delivers best in class NECG for 40G and 100G metro applications," in 2010 Conference on Optical Fiber Communication (OFC/NFOEC), collocated National Fiber Optic Engineers Conference, 2010, pp. 1-3, doi: 10.1364/NFOEC.2010.NTuB3.

[47] Y. Miyata, K. Kubo, K. Onohara, W. Matsumoto, H. Yoshida, and T. Mizuochi, "UEP-BCH product code based hard-decision FEC for 100 $\mathrm{Gb} / \mathrm{s}$ optical transport networks," in OFC/NFOEC, 2012, pp. 1-3.

[48] I. PMC-Sierra, Swizzle FEC for $40 G$ and $100 G$ Optical Transmission White Paper. January, 2011.

[49] Y. Jian, H. D. Pfister, K. R. Narayanan, Raghu Rao, and R. Mazahreh, "Iterative hard-decision decoding of braided $\mathrm{BCH}$ codes for highspeed optical communication," in 2013 IEEE Global Communications Conference (GLOBECOM), 2013, pp. 2376-2381, doi: 10.1109/GLOCOM.2013.6831429.

[50] M. Barakatain and F. R. Kschischang, "Low-Complexity Concatenated LDPC-Staircase Codes," Journal of Lightwave Technology, vol. 36, no. 12, pp. 2443-2449, Jun. 2018, doi: 10.1109/JLT.2018.2812738

[51] L. M. Zhang and F. R. Kschischang, "Low-Complexity Soft-Decision Concatenated LDGM-Staircase FEC for High-Bit-Rate Fiber-Optic Communication," Journal of Lightwave Technology, vol. 35, no. 18, pp. 3991-3999, Sep. 2017, doi: 10.1109/JLT.2017.2716373.

[52] K. Cushon, P. Larsson-Edefors, and P. Andrekson, "Improved LowPower LDPC FEC for Coherent Optical Systems," in 2017 European Conference on Optical Communication (ECOC), 2017, pp. 1-3, doi: 10.1109/ECOC.2017.8345844.

[53] D. A. Morero et al., "Experimental demonstration of a variable-rate LDPC code with adaptive low-power decoding for next-generation optical networks," in 2016 IEEE Photonics Conference (IPC), 2016, pp. 307-308, doi: 10.1109/IPCon.2016.7831110

[54] T. Koike-Akino et al., "Iteration-Aware LDPC Code Design for LowPower Optical Communications," Journal of Lightwave Technology, vol. 34, no. 2, pp. 573-581, Jan. 2016, doi: 10.1109/JLT.2015.2477881.

[55] K. Ishii et al. " $100 / 150 / 200 \mathrm{~Gb} / \mathrm{s}$ real-time demonstration of SD-FEC employing MSSC-LDPC codes for flexible coherent transport," in 2017 Opto-Electronics and Communications Conference (OECC) and Photonics Global Conference (PGC), 2017, pp. 1-2, doi: 10.1109/OECC.2017.8114879.

[56] K. Sugihara, S. Kametani, K. Kubo, T. Sugihara, and W. Matsumoto, "A practicable rate-adaptive FEC scheme flexible about capacity and distance in optical transport networks," in 2016 Optical Fiber Communications Conference and Exhibition (OFC), 2016, pp. 1-3

[57] L. Beygi, E. Agrell, J. M. Kahn, and M. Karlsson, "Rate-Adaptive Coded Modulation for Fiber-Optic Communications," Journal of Lightwave Technology, vol. 32, no. 2, pp. 333-343, Jan. 2014, doi: 10.1109/JLT.2013.2285672.

[58] Yequn Zhang and I. B. Djordjevic, "Staircase rate-adaptive LDPCcoded modulation for high-speed intelligent optical transmission," in OFC 2014, 2014, pp. 1-3, doi: 10.1364/OFC.2014.M3 A.6.

[59] T. Fehenberger, G. Böcherer, A. Alvarado, and N. Hanik, "LDPC coded modulation with probabilistic shaping for optical fiber systems," in 2015 Optical Fiber Communications Conference and Exhibition (OFC), 2015, pp. 1-3, doi: 10.1364/OFC.2015.Th2A.23

[60] M. Arabaci, I. B. Djordjevic, R. Saunders, and R. M. Marcoccia "Rate-adaptive non-binary-LDPC-coded polarization-multiplexed multilevel modulation with coherent detection for optically-routed networks," in 2009 11th International Conference on Transparent Optical Networks, 2009, pp. 1-4, doi: 10.1109/ICTON.2009.5185083.
[61] Y. Aikawa and H. Uenohara, "Demonstration of Optical FEC Coding Scheme With Convolutional Code Consisting of a Signal Source," IEEE Photonics Technology Letters, vol. 29, no. 1, pp. 165-168, Jan. 2017, doi: 10.1109/LPT.2016.2631258.

[62] Y. Aikawa and H. Uenohara, "Experimental demonstration of alloptical FEC coding scheme with convolutional code," in $201621 \mathrm{st}$ OptoElectronics and Communications Conference (OECC) held jointly with 2016 International Conference on Photonics in Switching (PS), 2016, pp. 1-3

[63] C. Kherici and M. Kandouci, "Contribution to the performances study of Optical Time Division Multiplexing OTDM and OTDM/WDM hybrid multiplexing at $160 \mathrm{Gbps,"} \mathrm{in} 2019$ International Conference on Wireless Technologies, Embedded and Intelligent Systems (WITS), 2019, pp. 1-4, doi: 10.1109/WITS.2019.8723826.

[64] N. Wada et al. "Space division multiplexing (SDM) transmission and related technologies," in 2014 16th International Telecommunications Network Strategy and Planning Symposium (Networks), 2014, pp. 1-

[65] V. Kachhatiya and S. Prince, "Analysis of dense wavelength division multiplexed passive optical network (DWDM-PON)," in 2017 International Conference on Communication and Signal Processing (ICCSP), 2017, pp. 1974-1978.

[66] R. Mishra, N. K. Shukla, M. Atif, and C. K. Dwivedi, "Performance Analysis of 8 Channel DWDM Systems via Dispersion Compensation Fiber Using NRZ, RZ, CSRZ Modulation Schemes,” in 2018 International Conference on Computer Communication and Informatics (ICCCI), 2018, pp. 1-6, doi 10.1109/ICCCI.2018.8441500.

[67] T. Islam and M. N. Uddin, " $240 \mathrm{Gbit} / \mathrm{s}$ bit compressed hybrid OTDMWDM fiber optic communication system," in 2017 IEEE Region 10 Symposium (TENSYMP), 2017, pp. 1-5, doi: 10.1109/TENCONSpring.2017.8070083.

[68] A. H. Ali, H. J. Alhamdane, and B. S. Hassen, "Design analysis and performance evaluation of the WDM integration with CO-OFDM system for radio over fiber system," Indonesian Journal of Electrical Engineering and Computer Science, vol. 15, no. 2, pp. 870-878, 2019.

[69] J. Ladrido, "Comparative Survey of Signal Processing and Artificial Intelligence Based Channel Equalization Techniques and Technologies," International Journal of Emerging Trends in Engineering Research, pp. 311-322, 2019, doi: 10.30534/ijeter/2019/14792019.

[70] G. E. Bottomley, Channel Equalization for Wireless Communications: From Concepts to Detailed Mathematics. Wiley, 2012 [Online]. Available: https://books.google.com.ph/books?id=ZUBbd2icM6IC

[71] I. B. Djordjevic, "Advances in error correction coding for high-speed optical transmission," in 2013 IEEE Photonics Conference, 2013, pp. 133-134, doi: 10.1109/IPCon.2013.6656407.

[72] M. Tao et al., "Improved Dispersion Tolerance for 50G-PON Downstream Transmission via Receiver-Side Equalization," in 2019 Optical Fiber Communications Conference and Exhibition (OFC), 2019, pp. 1-3.

[73] H. Zheng, A. Shen, N. Cheng, N. Chand, F. Effenberger, and X. Liu, "High-Performance 50G-PON Burst-Mode Upstream Transmission at $25 \mathrm{~Gb} / \mathrm{s}$ with DSP-Assisted Fast Burst Synchronization and Recovery," in 2019 Asia Communications and Photonics Conference (ACP), 2019, pp. 1-3.

[74] J. Wei et al., "Demonstration of the First Real-Time End-to-End 40Gb/s PAM-4 for Next-Generation Access Applications Using 10-Gb/s Transmitter," Journal of Lightwave Technology, vol. 34, no. 7, pp. 1628-1635, Apr. 2016, doi: 10.1109/JLT.2016.2518748.

[75] J. Xia, T. Xu, Z. Li, Y. Li, Q. Zhang, and M. Wang, "Investigation on adaptive equalization techniques for 10G-glass optics based 100GPON system," in 2017 Opto-Electronics and Communications Conference (OECC) and Photonics Global Conference (PGC), 2017, pp. 1-3, doi: 10.1109/OECC.2017.8114834.

[76] D. Zibar, J. Thrane, J. Wass, R. Jones, M. Piels, and C. Schaeffer, "Machine learning techniques applied to system characterization and equalization," in 2016 Optical Fiber Communications Conference and Exhibition (OFC), 2016, pp. 1-3.

[77] E. Giacoumidis et al., "Reduction of Nonlinear Intersubcarrie Intermixing in Coherent Optical OFDM by a Fast Newton-Based Support Vector Machine Nonlinear Equalizer," Journal of Lightwave Technology, vol. 35, no. 12, pp. 2391-2397, Jun. 2017, doi 10.1109/JLT.2017.2678511

[78] J. Zhang, W. Chen, M. Gao, B. Chen, and G. Shen, "Novel LowComplexity Fully-Blind Density-Centroid - Tracking Equalizer for 64-QAM Coherent Optical Communication Systems," in 2018 Optical 
Fiber Communications Conference and Exposition (OFC), 2018, pp. $1-3$.

[79] J. Torres-Zugaide, I. Aldaya, G. Campuzano, E. Giacoumidis, J. Beas, and G. Castañón, "Range extension in coherent OFDM passive optical networks using an inverse Hammerstein nonlinear equalizer," IEEE/OSA Journal of Optical Communications and Networking, vol. 9, no. 7, pp. 577-584, Jul. 2017, doi: 10.1364/JOCN.9.000577.

[80] S. T. Ahmad and K. P. Kumar, "Radial Basis Function Neural Network Nonlinear Equalizer for 16-QAM Coherent Optical OFDM," IEEE Photonics Technology Letters, vol. 28, no. 22, pp. 2507-2510, Nov. 2016, doi: 10.1109/LPT.2016.2601901.

[81] T. Nguyen, S. Mhatli, E. Giacoumidis, L. V. Compernolle, M. Wuilpart, and P. Mégret, "Fiber Nonlinearity Equalizer Based on Support Vector Classification for Coherent Optical OFDM," IEEE Photonics Journal, vol. 8, no. 2, pp. 1-9, Apr. 2016, doi: 10.1109/JPHOT.2016.2528886

[82] X. Zhou et al., "Low-Complexity One-Step Digital Back-Propagation for Single Span High-Capacity Coherent Transmissions," IEEE Photonics Journal, vol. 9, no. 3, pp. 1-11, Jun. 2017, doi: 10.1109/JPHOT.2017.2702379.

[83] S. Mhatli, H. Mrabet, I. Dayoub, and E. Giacoumidis, "A novel support vector machine robust model based electrical equaliser for coherent optical orthogonal frequency division multiplexing systems," IET Communications, vol. 11, no. 7, pp. 1091-1096, 2017, doi: 10.1049/iet-com.2016.1115.

[84] E. Giacoumidis, A. Matin, J. Wei, N. J. Doran, L. P. Barry, and X Wang, "Blind Nonlinearity Equalization by Machine-Learning-Based Clustering for Single- and Multichannel Coherent Optical OFDM," Journal of Lightwave Technology, vol. 36, no. 3, pp. 721-727, Feb. 2018, doi: 10.1109/JLT.2017.2778883.

[85] R. Koma, M. Fujiwara, J. Kani, K. Suzuki, and A. Otaka, "Burst-mode digital signal processing that pre-calculates FIR filter coefficients for digital coherent pon upstream," IEEE/OSA Journal of Optical Communications and Networking, vol. 10, no. 5, pp. 461-470, May 2018, doi: 10.1364/JOCN.10.000461.

[86] J. Cheng, C. Xie, M. Tang, and S. Fu, "Hardware Efficient Adaptive Equalizer for Coherent Short-Reach Optical Interconnects," IEEE
Photonics Technology Letters, vol. 31, no. 15, pp. 1249-1252, Aug. 2019, doi: 10.1109/LPT.2019.2924465.

[87] E. Giacoumidis, A. Tsokanos, M. Ghanbarisabagh, S. Mhatli, and L. P. Barry, "Unsupervised Support Vector Machines for Nonlinear Blind Equalization in CO-OFDM," IEEE Photonics Technology Letters, vol. 30, no. 12, pp. 1091-1094, Jun. 2018, doi: 10.1109/LPT.2018.2832617.

[88] X. Zhang et al., "Joint Polarization Tracking and Equalization in RealTime Coherent Optical Receiver," IEEE Photonics Technology Letters, vol. 31, no. 17, pp. 1421-1424, Sep. 2019, doi: 10.1109/LPT.2019.2929824.

[89] A. Bakhshali et al., "Frequency-Domain Volterra-Based Equalization Structures for Efficient Mitigation of Intrachannel Kerr Nonlinearities," Journal of Lightwave Technology, vol. 34, no. 8, pp. 1770-1777, Apr. 2016, doi: 10.1109/JLT.2015.2510607.

[90] Y. Fazea, A. Amphawan, Y. Al-Gumaei, A. M. Al-Samman, and W. M. Al-Rahmi, "Modes power equalization based-singular value decomposition in mode division multiplexing systems for multihungry bandwidth applications," Optical Fiber Technology, vol. 61, p. 102389, Jan. 2021.

[91] E. Giacoumidis, Y. Lin, M. Blott, and L. P. Barry, "Real-time machine learning based fiber-induced nonlinearity compensation in energyefficient coherent optical networks," APL Photonics, vol. 5, no. 4, p. 041301, 2020, doi: 10.1063/1.5140609.

[92] D. Zabala-Blanco, M. Mora, C. A. Azurdia-Meza, A. Dehghan Firoozabadi, P. Palacios Játiva, and I. Soto, "Relaxation of the RadioFrequency Linewidth for Coherent-Optical Orthogonal FrequencyDivision Multiplexing Schemes by Employing the Improved Extreme Learning Machine," Symmetry, vol. 12, no. 4, p. 632, 2020, doi: $10.3390 /$ sym 12040632 .

[93] X. Zhang et al., "Real time low-complexity adaptive channel equalization for coherent optical transmission systems," Opt. Express, vol. 28 , no. 4 , pp. 5058-5068, Feb. 2020, doi: 10.1364/OE.385370. [Online]. Available: http://www.opticsexpress.org/abstract.cfm?URI=oe-28-4-5058 